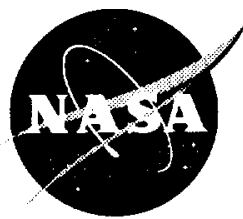

\title{
Development of Thermal Barriers for Solid Rocket Motor Nozzle Joints
}

Bruce M. Steinetz

Glenn Research Center, Cleveland, Ohio

Patrick H. Dunlap, Jr.

Modern Technologies Corporation, Middleburg Heights, Ohio

Prepared for the 35th Joint Propulsion Conference and Exhibit cosponsored by the AIAA, ASME, SAE, and ASEE Los Angeles, California, June 20-24, 1999

National Aeronautics and Space Administration

Glenn Research Center 


\section{Acknowledgments}

The authors greatly acknowledge Doug Frost's and Steve Hicken's (Thiokol) thermal barrier test results; Bruce Bond's (Albany-Techniweave) assistance in fabricating the thermal barriers; and Tom Doeberling's and Lauren Yee's (NASA) assistance in test support.

Trade names or manufacturers' names are used in this report for identification only. This usage does not constitute an official endorsement, either expressed or implied, by the National Aeronautics and Space Administration.

Available from

NASA Center for Aerospace Information

7121 Standard Drive

Hanover, MD 21076

Price Code: A03
National Technical Information Service 5285 Port Royal Road Springfield, VA 22100

Price Code: A03 


\title{
AIAA-99-2823 \\ DEVELOPMENT OF THERMAL BARRIERS FOR SOLID ROCKET MOTOR NOZZLE JOINTS
}

\author{
Bruce M. Steinetz* \\ National Aeronautics and Space Administration \\ Glenn Research Center \\ Cleveland, Ohio 441.35 \\ Patrick H. Dunlap, Jr." \\ Modern Technologies Corporation \\ Middleburg Heights, Ohio 44130
}

\begin{abstract}
The Space Shuttle solid rocket motor case assembly joints are sealed using conventional (O-ring seals. The $5500+{ }^{\circ} \mathrm{F}$ combustion gases are kept a safe distance away from the seals by thick layers of insulation. Special jointfill compounds are used to fill the joints in the insulation to prevent a direct flowpath to the seals. On a number of occasions, NASA has observed in several of the rocket nozzle assembly joints hot gas penetration through defects in the joint-fill compound. The current nozzle-to-case joint design incorporates primary, secondary and wiper (innermost) O-rings and polysulfide joint-fill compound. In the current design. 1 out of 7 motors experience hot gas to the wiper ()-ring. Though the condition does not threaten motor safety. evidence of hot gas to the wiper (O-ring results in extensive reviews before resuming flight. NASA and solid rocket motor manufacturer Thiokol are working to improve the nozzle-to-case joint design by implementing a more reliable $J$-leg design and a thermal barrier.

This paper presents burn-resistance, temperature drop. flow, and resiliency test results for several types of NASA braided carbon-fiber thermal barriers. Burn tests were performed to determine the time to burn through each of the thermal barriers when exposed to the flame of an oxyacetylene torch $\left(5500{ }^{\circ} \mathrm{F}\right.$ ), representative of the $5500^{\circ} \mathrm{F}$ solid rocket motor combustion temperatures. Thermal barriers braided out of carbon fibers endured the flame for over $6 \mathrm{~min}$. three times longer than the solid rocket motor burn time. Tests were performed on two thermal barrier braid architectures, denoted Carbon- 3 and Carbon- 6 , to measure the temperature drop across and along the barrier in a compressed state when subjected to the flame of an oxyacetylene torch. Carbon- 3 and Carbon-6 thermal barriers were excellent insulators causing temperature drops through their diameter from 2500 to $2800^{\circ} \mathrm{F}$. Gas temperatures $1 / 4$ " downstream of the thermal barrier were within the downstream Viton ()-ring temperature limit of
\end{abstract}

\footnotetext{
* Senior Research Engincer. Mechanical Components Branch. Member AIAA.

Research kingineer.
}

$600^{\circ} \mathrm{F}$. Carbon- 6 performed extremely well in subscale rocket "char" motor tests when subjected to hot gas at $3200^{\circ} \mathrm{F}$ for an 11 -sec. rocket firing. simulating the maximum downstream joint cavity fill time. The thermal barrier reduced the incoming hol gas temperature by $2200^{\circ} \mathrm{F}$ in an intentionally oversized gap defect, spread the incoming jet flow, and blocked hot slag, thereby offering protection to the downstream O-rings.

\section{Introduction}

The need for high temperature $\left(1500\right.$ to $\left.2000^{\circ} \mathrm{F}\right) \mathrm{com}$ pliant seals in advanced gas turbine engine designs led to the development of rope seals braided out of newly developed ceramic fibers and superalloy wires. Previous seal research yielded several braided rope seal designs that demonstrated the ability to both seal and serve as compliant mounts under aggressive temperature and pressure requirements. ${ }^{1,2}$ However, Steinetzand Dunlap ${ }^{3}$ showed that these seals do not last for more than a few seconds when subjected to the extremely hot $5500+{ }^{\circ} \mathrm{Fcombustion}$ gases that are found in the Space Shuttle Solid rocket motor. Thus. other materials were considered to evolve the braided rope seal design into a thermal barrier for use at extreme transient temperatures.

The Space Shuttle reusable solid rocket motor (RSRM) assembly joints are sealed using conventional $O$-ring seals. The 550()$+{ }^{\circ} \mathrm{F}$ combustion gases are kept a safe distance away from the seals by thick layers of phenolic or rubber insulation. Special joint-fill compounds are used to fill the joints in the insulation to prevent a direct flow-path to the seals. Normally, these two stages of protection are enough to prevent a direct thowpath of the 900 -psi hot gases from reaching the seals. Occasionally, seals have experienced charring due to parasitic leakage paths that open up in the

\footnotetext{
Copyright (1) 1999 by the American Institute of Aeronautics and Astronautics, Ins. No copyright is asserted in the United States under Title 17. U.S. Code. The U.S. Government has a royalty-free license to exercise all rights under the copyright claimed herein for Governmental Purposes. All other rights are reserved by the copyright owner.
} 
joint-fill compounds during rocket operation. Inspection during disassembly of Space Shuttle solid rocket motor nozzle joints from RSRM-44 and RSRM-45 revealed O-ring erosion of Joint 3 primary O-ring seals ${ }^{4}$ (Fig. 1). Subsequent improvements in joint-fill compound application-techniques have apparently overcome the Joint 3 charring problem. However, a number of nozzle joints including the nozzle-to-case joint and Joint 2 continue to show hot gas penetration through the joint fill compound. The current nozzle-to-case joint design incorporates primary. secondary and wiper (innermost) O-rings and polysulfide joint-fill compound. In the current design, I out of 7 motors experience hot gas to the wiper ()-ring. Though the condition does not threaten motor safety, evidence of hot gas to the wiper ()-ring results in extensive reviews before resuming flight. NASA and solid rocket motor manufacturer Thiokol are working to improve the nozzle-10-case joint design by implementing a more reliable J-leg design and a thermal barrier, and eliminate the jointfill compound (Fig. 1). The J-leg is molded into the insulation and contacts the mating surface of the adjoining element. Rocket pressurization acts to further preload the $\mathrm{J}$-leg increasing its effectiveness. The basic J-leg design has been applied successfully to fixing the field joints in the redesign effort following the Challenger accident.5 The thermal barrier, compressed between the J-leg and adjoining element. is intended to resist any hot gases the J-leg does not block and prevent them from reaching the wiper ()-ring. The braided carbon thermal harrier being developed at NASA Glenn is the leading candidate based on the results presented herein.

The thermal barrier for the Shuttle solid rocket motor has unique requirements, including the following. amongst others:

1. Sustain extreme temperatures $\left.(2500 \text { to } 5500)^{\circ} \mathrm{F}\right)$ during solid rocket motor burn ( $2 \mathrm{~min}$ and $4 \mathrm{sec}$.) without loss of integrity.

2. Drop incoming gas temperatures (up to $3200^{\circ} \mathrm{F}$ ) in the joint to levels acceptable to Viton O-rings $(\leq 600)^{\circ} \mathrm{F}$, short-term) to prevent O-ring damage, including char and erosion.

3. Exhibit some permeability to permit the joint cavity (between thermal barrier and O-ring) to reach chamber pressure (900-psi) in acceptable time.

4. Exhibil adequate resiliency/springback to accommodate limited joint movement and manufacturing tolerances in these large $(8.5 \mathrm{ft}$. diam.) nozzle segments.

5. Diffuse/spread incoming narrow (0.08 in. diam.) hot gas jets to reduce their damaging effects on the downstream O-rings.

6. Block hot slag (i.e., molten alumina. etc.) entrained in gas stream from reaching $\mathrm{O}$-rings.
Steinetz and Dunlap ${ }^{3}$ performed a number of tests on 0.125 -and 0.200 -in. diameter braided carbon-fiber thermal barriers demonstrating that they met the burn-resistance, permeability, and resiliency criteria.

The main objective of the current study is to fully characterize two braided carbon fiber thermal barrier designs (denoted Carbon-3 and Carbon-6) by assessing their transient thermal response when subjected to a high temperature torch and by characterizing their permeability, resiliency, and burn-resistance. The Carbon-6 design is currently being tested by both NASA and Thiokol for the nozzle-to-case joints of the Shuttle solid rocket motor. Subscale rocket "char" motor tests were performed to assess the thermal barrier's (Carbon-6) thermal response and heat resistance under actual rocket conditions.

\section{Test Apparatus and Procedures}

\section{Thermal Barrier Specimens}

Carbon- 3 and Carbon- 6 were subjected to burn, temperature drop, flow, and compression tests. Carbon-6 was also tested in a subscale char motor. Limited testing was performed on the Carbon-4 design. Table I summarizes the relevant architecture parameters for the thermal barricr designs that were tested.

All thermal barriers were composed of a uniaxial core of fibers overbraided with various numbers of sheath layers. The Carbon-6 design had ten sheath layers and a 0.26-in. diameter. Carbon- 6 had good flexibility and compliance properties because it was braided with a more open architecture. The Carbon-3 design had a 0.20-in. diameter and was made with a large degree of uniaxial core fibers overbraided with five sheath layers. Carbon- 3 was a tight braid that was not as flexible as Carbon-6. Carbon- 4 had $4.4 \times 10^{-4}$ in. $(11 \mu \mathrm{m})$ pitch-based Amoco $P 25$ fibers in its core to evaluate core fiber diameter effects on performance, while the core fibers of all the other carbon thermal barriers were $2.76 \times 10^{-4}$ in. $(6.9 \mu \mathrm{m})$ PAN-based Grafil type 34 700 fibers. PAN-based Thornel T-300 carbon fibers with a $2.8 \times 10^{-4}$ in. $(7 \mu \mathrm{m})$ diameter were used in the sheaths of all the thermal barrier designs.

\section{Thermal Barrier Porosity Measurements}

To assess thermal barrier porosity while under compression. samples of the Carbon- 3 and Carbon- 6 designs were examined in a compressed state using a photographic stereomicroscope. Four 1/2-in. long specimens of both types of thermal barriers were prepared and weighed using a precision electronic balance. The exact length of each specimen was measured using vernier calipers. Each specimen was then clamped between two steel plates and subjected to a $20 \%$ compression. While the specimens were compressed, a light layer of cyanoacrylic glue was applied to the surface 
of each specimen so that they would maintain their compressed shape upon removal from the fixture.

Four specimens were examined for hoth Carbon-3 and Carbon-6. Bothends of each specimen were examined and photographed at $10 \mathrm{X}$ in the microscope so that eight cross section photos were examined for both thermal barrier designs. Each cross section assumed an ellipsoidal shape in its compressed state. The dimensions of each ellipse were measured using vernier calipers. These dimensions were then used to calculate the cross sectional - area of both ends of each specimen. An average cross sectional area was calculated for each specimen and multiplied by the specimen length to determine the specimen volume. Specimen density was then calculated by dividing the weight of the specimen by its volume. An average density at $20 \%$ compression was found for both Carbon- 3 and Carbon- 6 by averaging the densities of the four specimens of each design. The porosity of each thermal harrier design at $20 \%$ compression was calculated using the following relationship:

$$
\text { Porosity }=1-\left(\rho_{\text {Thermal Barrier }} / \rho_{\text {Carton Fiber }}\right)
$$

In this relationship, the density of each thermal harrier design was divided by the density of an individual carbon fiber $(0.064 \mathrm{lb} / \mathrm{cu} . \mathrm{in}$.). Thus, a thermal barrier design would have a porosity of zero if it had no gaps and assumed the density of an individual fiber.

\section{Burn Tests}

A screening test was developed to evaluate thermal barrier burn resistance under simulated rocket motor combustion temperatures $\left(5500^{\circ} \mathrm{F}\right)$ by aiming a "neutral" flame $^{6}$ of an oxyacetylene welding torch at the center section of a 4 -in. thermal barrier specimen. In these tests, the amount of time required to completely cut through the specimen was measured. Time for cut-through was measured from the instant the flame touched the specimen until the specimen was completely cut into two separate pieces. A detailed description and an illustration of the fixture used 10 perform these tests can be found in the paper by Steinetz and Dunlap. ${ }^{3}$

\section{Temperature Drop Tests}

A test fixture was developed to measure the temperature drop across and along the thermal barriers in a compressed state when subjected to the neutral flame of an oxyacetylene torch simulating rocket temperatures (Fig. 2). Flow was drawn through the thermal barrier using a vacuum roughing pump to lower pressure on the downstream side of the thermal barrier while leaving the upstream side at ambient conditions. Flow through the thermal harrier was measured using a flow meter positioned between the fixture and the roughing pump. The volume downstream of the thermal barrier was an enclosed plenum chamber sealed by an O-ring between the bottom plate and a top plate. The thermal barrier was compressed at $20 \%$ linear compression. Other compressions are possible by placing shims under the thermal barrier. The fixture was made out of phenolic insulation having low thermal conductivity that simulates the solid rocket motor insulating material and minimizes parasitic heat loss.

The torch flame was applied to the thermal barrier to simulate a leak path of hot gases through the nozzle joint. The flame with temperatures up to $3200^{\circ} \mathrm{F}$ was positioned on a small area of the thermal harrier. An "iris plate" with a 0.084-in. diameter hole concentrated a "laser-like" column of flame onto the thermal barrier. simulating a hot gas jet flowing through the rocket nozzle joint. The iris plate was positioned about 1/4-in. away from the specimen. The jet was directed at the center of the specimen both span- and height-wisc.

To measure the surface temperature distribution along the thermal barrier span, thermocouples were placed on both the upstream (hot) and downstream (cold) sides. The thermal barrier specimen sat between these two rows of thermocouples in a 0.040 -in.-deep groove. The thermocouples measured how the llame spread along the thermal barrier, how much temperature drop occurred across the thermal harrier, and how heat was conducted along its length. The fixture was instrumented with seven thermocouples upstream of the thermal barrier and eight downstream thermocouples. On the upstream side, the center Type B thermocouple was placed directly in line with the center of the hole in the iris plate so that it measured the hottest flame temperature at the surface of the thermal barrier. Type B thermocouples were then positioned 1/4-in. on either side of the center thermocouple (Fig. 2). The remaining four thermocouples on the hot side were Type $\mathrm{K}$ thermocouples, and they were placed $1 / 2$ and 1 in. on either side of the center thermocouple. Seven of the eight Type $\mathrm{K}$ thermocouples downstream of the thermal barrier were spaced so that they were directly in line with those upstream of the thermal harrier. The remaining Type $\mathrm{K}$ thermocouple was positioned $1 / 4$ in. (approximately one thermal harrier diameter) downstream of the thermal barrier in line with the center thermocouple and measured the bulk air temperature.

Thermocouple selection. Fine gage wire open-bead thermocouples were used to quickly and accurately measure changes in the surface temperature distribution along the thermal barrier. The time constant and response rate of a thermocouple is controlled by the size of its wires and the diameter of the junction ball that is formed between the wires. The wire diameters used for the Type $B$ and Type $K$ thermocouples were 0.010 and $0.0125 \mathrm{in}$., respectively. A typical thermocouple junction hall has a diameter about $50 \%$ larger than the wires in the thermocouple. Calculations 
of the time constants for junction balls with a diameter of 0.015 to $0.019 \mathrm{in}$. showed that these thermocouples would have a time constant of about $1 / 2 \mathrm{sec}$.

Pressure/Flow Transducers. An absolute pressure Iransducer measured the pressure upstream of the thermal barrier while a differential transducer measured the pressure drop across a specimen. Flow through the thermal barrier was measured using a () to 100 SLPM flowmeter. Data was acquired from all of this instrumentation at a sampling rate of $10 \mathrm{~Hz}$ using Keithley data acquisition hardware and Lablech Notebook software.

For each test, a 5-in. thermal barrier specimen was prepared and installed into the groove in the fixture. The I4 thermocouples that measured the surface temperature along the specimen were slipped into the outer sheath layer of the thermal barrier and adjusted so that they were spaced properly. To prevent parasitic leakage, the plenum chamber (O-ring was then positioned so that it was snug against the ends of the thermal barrier. The vacuum pump was turned on for several minutes, to cause the pressure drop and to achieve a steady flow rate through the specimen before applying the torch. The oxyacetylene torch was adjusted until a neutral flame was formed. The torch was slid along a machined groove until it was properly positioned in front of the hole in the iris plate. The torch was left on the specimen for 30 or $60 \mathrm{sec}$, and then pulled away from the fixture and shut off. Sometimes repeat tests were performed on the same specimen to examine the effects of repeated flame exposures. Torch nozzle spacing to the iris plate proved to be important in controlling the maximum hot side temperature without melting the center Type B thermocouple (platinum-rhodium. $\mathrm{T}_{\text {melt }}=$ $3308{ }^{\circ} \mathrm{F}$ ). Torch spacings for Carbon-3 and Carbon-6 were 0.265 and $0.160 \mathrm{in}$. respectively.

\section{Flow Tests}

Flow tests were performed on the thermal barriers in a high temperature flow and durability test rig shown schematically in Fig. 3. The test rig is capable of operating at temperatures from room temperature to $1500{ }^{\circ} \mathrm{F}$. pressures between ( $)$ and 100 psig. and $170 w s$ of 0 10 3.5 SCFM (standard cubic feet per minute, conversion I SCFM = 28.3 SLPM). Specimen length was $7.50 \pm 0.05$ in., and the thermal harriers were mounted into a groove in the piston. The free ends of the specimens were joined together in the piston groove using a $1 / 4$ in. lap joint. Preload was applied to the specimens through a known interference fit between the thermal barrier and the cylinder inner diameter. To vary the amount of preload, the interference fit was modified by mounting different thicknesses of stainless steel shims behind the specimen in the piston groove. During flow testing. hot pressurized air entered at the base of the cylinder and flowed to the test specimen that sealed the annulus created by the cylinder and piston walls $(0.007 \mathrm{in}$. radial gap). The durability of the thermal barriers at high temperatures was examined by subjecting them to scrub cycles in which the piston and thermal barrier were reciprocated in the cylinder.

Flow data was recorded before scrubbing at temperatures of 70 and $500^{\circ} \mathrm{F}$ and after scrubbing at 70,500 , and $900^{\circ} \mathrm{F}$. Specimens were subjected to ten scrub cycles at $500^{\circ} \mathrm{F}$. At each temperature, flow data was recorded at pressures of $2,5,10,30,60,90$, and 100 psid (or as high as could be recorded within the limits of the flowmeters) with the downstream pressure at ambient pressure. Primary and repeat flow tests were performed on the Carbon- 3 and Carbon-4 designs for a diametral or linear compression of 0.040 and 0.050 in. (20 and $25 \%$ linear compression) and on the Carbon- 6 design at linear compressions of 0.052 and 0.065 in. ( 20 and $25 \%$ linear compressions). A detailed description of the hardware and procedure used to perform these tests can be found in the papers by Steinetz et al. ${ }^{1}$ and Steinet $z$ and Adams. ${ }^{2}$

\section{Compression Tests}

Compression tests were performed to determine thermal barrier preload and resiliency behavior at room temperature using a precision linear slide compression test fixture shown schematically in Fig. 4. A 1 1/2-in. long specimen was loaded into a stationary grooved specimen holder, and an opposing plate was compressed against the specimen. Stainless steel shims were placed in the groove behind the specimens to vary the amount of linear compression. The amount of compressive load on the specimen was measured versus the amount of compression. Multiple load cycles were applied to the specimen before the preload data point was recorded to remove effects of the hysteresis and permanent set that accumulate with load cycling of the specimens. Most permanent set occurred within the first four load cycles. A pressure sensitive film mounted on the opposing plate was used to determine the contact width of the specimen as it was compressively loaded. The footprint length (nominal 1 in.) and width at the end of the fourth load cycle were used along with the measured load versus compression data to calculate the estimated preload and residual interference corresponding to a given linear crush value.' Residual interference is defined as the distance the specimen will spring back while maintaining a load of at least $\mathrm{I} \mathrm{lb} / \mathrm{in}$. of specimen.

Compression tests were performed on the Carbon-3 and Carbon- 6 designs to determine the specimen preloads corresponding to the linear crushes used in the flow experiments. Tests were performed at compressions of 20 , 25 , and $30 \%$ of each specimen's overall diameter. Primary and repeat compression tests were performed. The hardware and procedure used to perform these tests are described in detail by Steinetz et al. ${ }^{1}$ 
Subscale Rocket "Char" Motor Tests

As part of the development process of the thermal barrier, Thiokol Corporation performed tests using a subscale $(70 \mathrm{lbm})$ rocket "char" motor. In these tests, the NASA Carbon-6 0.260-in. cross-sectional diameter thermal barrier impeded hot gas flow through an intentional circumferential defect between rocket-case insulation blocks. The thermal barrier compression was $20 \%$. The insulation blocks were modified to accommodate a 5 1/8-in. diameter thermal barrier. The 0.060 -in. defect was much larger than any defects that would normally form through the gap-fill material in the actual rocket nozzle joint, but this size was chosen to force gas flow through the thermal barrier under very extreme conditions. Burning solid rocket propellant, the rocket fired for $11 \mathrm{sec}$. and generated $900 \mathrm{psi}$ pressures and $5000{ }^{\circ} \mathrm{F}$ (estimated) chamber temperatures. Hot gas flowed to the thermal harrier while upstream and downstream temperatures and pressures were recorded. The char motor incorporated an outboard plenum chamber, or reservoir, to simulate the volume $\left(80\right.$ in. $\left.{ }^{3}\right)$ between the thermal barrier and the Viton ( )-ring seals. This reservoir ensured that flow would pass through the thermal barrier. The reservoir started at ambient pressure and then quickly reached chamber pressure, simulating the actual RSRM joint fill-time. After the volume between the thermal barrier and Viton $\mathrm{O}$-ring pressurizes in the rocket nozzle joint. charring risk to the Viton O-ring is virtually eliminated.

\section{Results and Discussion}

\section{Thermal Barrier Porosity Measurements}

Measured values for thermal barrier density and porosity at $20 \%$ compression are presented in Table II for the Carbon- 3 and Carbon- 6 thermal harrier designs. A $20 \%$ compression level was chosen, as this is the compression level selected for the nozzle-to-case joint thermal barrier. The densities/porosities of braided structures are important for understanding their thermal and flow response characteristics.

Carbon- 3 had a higher density $(0.041 \mathrm{lb} / \mathrm{cu}$.in. $)$ and a lower porosity (0.37) than did Carbon- $6(0.032 \mathrm{lb} / \mathrm{cu}$.in. and 0.50 , respectively). This can be attributed to the differences in braid architecture between these two designs as shown in Table I. Carbon- 3 had a core composed of ten uniaxial $12 \mathrm{~K}$ yarns of Grafil $34-700$ carbon fibers-a large fraction of its cross-section. while Carbon-6 only had one $12 \mathrm{~K}$ yarn in its core. Carbon-6 had ten sheath layers of braided carbon fibers, while Carbon- 3 only had five layers. Carbon- 6 also had a lower sheath braid angle and fewer carriers per sheath layer to produce a softer, more flexible thermal harrier. Because the uniaxial fibers in the core pack together much better than the braided fibers that cross over each other in the sheath, the Carbon- 3 design with a greater percentage of core fibers is naturally more dense and less porous. Steinetz and Dunlap ${ }^{3}$ showed previously that the density of a braided carbon thermal barrier was inversely related to the number of sheath layers.

\section{Burn Test Results}

The amount of time to burn through each type of thermal barrier is shown in Fig. 5. In this ligure, the number of specimens that were tested is given next to the name of each thermal barrier type, and the average hurnthrough time is found above each bar. As shown previously by Steinetz and Dunlap. ${ }^{3}$ carbon fiber thermal barriers were the most burn-resistant. Figure 5 summarizes the earlier lests done on $1 / 8$-in. diameter stainless steel rods. Viton O-rings, and all-ceramic braided rope seals. It also shows the burn times of the 1/8-in. diameter (Carbon-1, Carbon-2. and Carbon-2A) and 0.200-in. diameter (Carbon- 3 and Carbon-4) carbon thermal barriers as well as new data on the burn time of the 0.260 )-in. diameter Carbon-6 design. The 1/8-in. diameter designs all endured the $5500{ }^{\circ} \mathrm{F}$ oxyacetylene torch for about $2 \mathrm{~min}$. Even more impressive burn times were seen for the 0.200 -in. diameter designs at about 6-1/2 $\mathrm{min}$. This is more than three times the Shuttle solid rocket motor burn time of $2 \mathrm{~min}, 4 \mathrm{sec}$. However. an increase in diameter to 0.260 in. did not produce an increase in burn time. Carbon-6 at 0.260 in. in diameter had a similar burn time to the 0.200-in. diameter designs at about 6-1/2 $\mathrm{min}$. Like the other carbon thermal barriers, Carbon- 6 was soft and flexible after removal from the flame, even in the area affected by the flame, with no evidence of charring or melting. All of the non-carbon specimens showed signs of charring or melting after removal from the flame. and many became very brittle in the area that was hurned.

The similarity in burn time between Carbon- 6 and the smaller-diameter Carbon- 3 and Carbon- 4 thermal barriers is believed to be related to the difference in porosity between these designs. As shown in Table II, Carbon- 6 is more porous than Carbon- 3 even in a compressed state. Steinetz and Dunlap ${ }^{3}$ theorized that the mass-loss mechanism during the oxyacetylene torch tests was carbon oxidation. Depending on material type, carbon fibers begin to oxidize at temperatures in the range of 600 to $900{ }^{\circ} \mathrm{F} .{ }^{7-9}$ The oxyacetylene torch burning at $5500{ }^{\circ} \mathrm{F}$ is hot enough to cause oxidation to occur, but too cool for carbon sublimation that occurs at $6900^{\circ} \mathrm{F} .{ }^{10} \mathrm{It}$ is believed that the looser, more porous braid of Carbon- 6 allowed more of the hot, oxidizing torch flame to pass through it. This allowed oxidation to occur more rapidly in the innermost fibers of Carbon- 6 than in the less porous Carbon-3 design. Even though there were more carbon fibers in the larger Carbon-6 design, they were cut through more quickly because they were exposed sooner to hot, oxidizing gases. These results indicate that burn/oxidation 
resistance is dependent on both thermal barrier diameter and porosity.

Products of combustion in the solid rocket motor include liquid alumina $\left(\mathrm{Al}_{2}, \mathrm{O}_{3}\right)$ and gaseous $\mathrm{CO}, \mathrm{ClO}_{2}, \mathrm{Cl}$, $\mathrm{HCl}$, and $\mathrm{H}_{2}$, none of which are oxidative. Hence, it is believed that the neutral flame in ambient air (oxidizing) is a conservative (i.e., more aggressive) environment for performing material screening burn tests. It is expected that oxidation rates within the rocket environment will be slower than those exhibited herein.

\section{Temperature Drop Test Results}

Temperature drop tests were performed on the Carbon- 3 and Carbon- 6 thermal barrier designs using the test fixture described that measured the temperature drop across and along the thermal barrier in a compressed state when subjected to the flame of an oxyacetylene torch. Figure 6 shows temperature versus time traces for a test performed on a Carbon-3 specimen. Data recorded from the center thermocouple and the three thermocouples to the right of center on both the hot and cold sides of the specimen are presented. Data from the thermocouples to the left of the center thermocouple is not shown in this figure for clarity. In general, the left and right sides produced symmetric data. Also shown in the figure is the temperature trace from the "cold bulk" $\left(T_{\text {bulk }}\right.$ ) thermocouple that measures the air temperature $1 / 4$ in. downstream of the specimen. For sensitivity purposes, we moved the $T_{\text {bulk }}$ thermocouple spatially to see if we were missing any local "hot-streaks." and we did not find any. Figure 7 shows temperature traces for a test performed on a Carbon- 6 specimen.

Examining Figs. 6 and 7. it can be seen that the center thermocouple on the hot side $\left(T_{\text {hot }}\right)$ and the center thermocouple on the cold side $\left(\mathrm{T}_{\text {cold }}\right)$ of the thermal harrier each recorded the hottest temperatures on their respeclive sides. This is expected as these thermocouples are directly in line with the hottest part of the torch flame as it passes through the hole in the iris plate. These figures also show that the temperature got progressively cooler from the center thermocouple to the R1, R2, and R3 thermocouples on the hot and cold sides of the specimen. This was also expected as the temperature decayed with movement further away from the center heat source.

Figures 6 and 7 show that there was a lag between increases in temperature on the hot and cold sides of the specimen. When the torch was applied to the thermal barrier, the hot side thermocouples instantly registered the increase in temperature. The insulating properties of the thermal barrier delayed heat conduction to the cold side, so the cold side thermocouples did not register an increase in temperature until several seconds after the torch was applied. The cold side temperatures measured were significantly lower than the hot side temperatures, as will be discussed below. After the torch was pulled away from the specimen, the hot side thermocouples instantly showed a decrease in temperature. The cold side thermocouples, though, continued to increase for 3 to $5 \mathrm{sec}$ before beginning to decrease in temperature. Comparing the hot side temperatures in Figs. 6 and 7, one notes fluctuations in temperature for Carbon-6 but nol Carbon-3. The origin of this fluctuation is unclear at this point, but we could find no system source of the variation (e.g. thermocouple integrity, etc.).

Figure 8 shows the temperature drop across specimens of Carbon- -3 and Carbon- 6 for flame applications of $\sim 30$ sec. The temperature drop was calculated as the difference between the temperature recorded by the hot side center thermocouple and the cold side bulk temperature $\left(\mathrm{T}_{\text {bulk }}\right)$. Over the 30 -sec. torch application, the temperature drop across the Carbon- 3 specimen dropped from a high of 2870 to $2680^{\circ} \mathrm{F}$ by the end of the test. This drop was caused by a steady rise in the cold side bulk temperature while the hot side temperature remained nearly constant. Carbon-6 exhibited a temperature drop in the range of 2980 to $2600{ }^{\circ} \mathrm{F}$. The uneven nature of the Carbon- 6 trace is due to fluctuations in the hot side temperature, as noted above. As shown by these figures, both Carbon- 3 and Carbon-6 thermal barrier designs caused a comparable temperature drop across the thermal barrier over a 30 -sec. torch flame application.

Figure 9 illustrates the symmetry of the temperature drop data for Carbon-3 and Carbon-6. Figure 9(a) shows the temperatures recorded by the seven hot and cold side thermocouples that were in contact with the surface of a Carbon- 3 specimen $15 \mathrm{sec}$. into the test. Though the downstream volume in the nozzle-to-case joint of the Shuttle solid rocket motors is expected to fill in $<10 \mathrm{sec}$., $15 \mathrm{sec}$. was chosen to include a safety factor of $5 \mathrm{sec}$. Figure $9(\mathrm{~b})$ shows similar data for a test performed on Carbon-6. Both figures show the temperature distribution from left to right across the hot and cold sides of the thermal barriers. The center thermocouples on the hot and cold sides correspond to a position of zero. Thermocouples to the left of center have a negative position value, while those to the right have a positive value. Both figures show a temperature distribution that is close to symmetric around the center thermocouples. Figure 9(a) shows that the data for this Carbon-3 test is shifted slightly to the right. Both figures show a temperature drop of about $2300^{\circ} \mathrm{F}$ between the hot $\left(\mathrm{T}_{\mathrm{hot}}\right)$ and cold $\left(\mathrm{T}_{\text {cold }}\right)$ center thermocouples in contact with the surface of the specimens.

Jet Spreading. The jet spreading capability of Carbon- 3 and Carbon- 6 is also shown in Fig. 9. Although the hot $\left(3000+{ }^{\circ} \mathrm{F}\right)$ torch was focused into a narrow (0.084-in. diam.) column, the thermal barrier spread the heat at least 1 in. on either side of the center thermocouples. Figure 9(a) shows that for Carbon-3, temperatures 1/4 in. away from the center hot side thermocouple were about 
$1200^{\circ} \mathrm{F}$ on the left side and over $2000^{\circ} \mathrm{F}$ on the right side. Hot side data for Carbon-6 in Fig. 9(b) show a similar trend with temperatures $1 / 4$ in. away from center over $2200^{\circ} \mathrm{F}$. Cold side data from both Figs. 9(a) and (b) show that the hot gas jet was reduced in temperature and diffused. Reducing the unit thermal energy per area is beneficial in preventing hot gas effects on the downstream O-rings.

Focused Jet Endurance Tests. Table III and Fig. 10 summarize the results of repeated temperature drop tests performed on single specimens of Carbon- 3 and Carbon- 6 to examine their endurance after multiple applications of the oxyacetylene torch. For both thermal barrier designs, a single specimen was subjected to the torch flame for two 30-sec. periods followed by two 6()-sec. periods. The exposure times of 30 and $60 \mathrm{sec}$. are longer than the joint cavity fill time of $10 \mathrm{sec}$. but were selected to examine the thermal barrier's insulation and flame resistance properties. After each exposure, the specimen was photographed (with fixture cover plate removed) to record any specimen damage before the next test was performed. For reference, the Carbon- 6 specimen was also exposed to a 20-sec. flame application before these endurance tests, and no damage was observed.

Table III shows several important temperature measurements for cach test alter $15 \mathrm{sec}$. as well as the flow through the specimen at fifteen seconds, the maximum bulk temperature reached during a test, and the amount of recession on the hot side of the specimen after the final flame exposure. The data for Carbon- 3 shows that tests 30 , 31 . and 32 were almost identical. Each showed a maximum hot side temperature slightly above $3000^{\circ} \mathrm{F}$ and a temperature drop $\left(\mathrm{T}_{\text {hot }}-\mathrm{T}_{\text {bulk }}\right)$ of over $2800^{\circ} \mathrm{F}$. The only difference between these tests was the higher maximum bulk temperature of $500{ }^{\circ} \mathrm{F}$ in test 32 . This was due to the longer flame exposure time that allowed the bulk temperature to keep increasing for $60 \mathrm{sec}$ as compared to the 30-sec exposures in tests 30 and 31 . The maximum hot side temperature in test 3.3 only reached $2590{ }^{\circ} \mathrm{F}$ compared to $3000+{ }^{\circ} \mathrm{F}$ in the other tests. This caused lower temperature differences across the specimen and lower bulk temperatures. For all four tests, the highest bulk temperature after $15 \mathrm{sec}$. was $230^{\circ} \mathrm{F}$. This is well below Viton's short term maximum operating temperature limit of $600^{\circ} \mathrm{F}$. ${ }^{\prime \prime}$ Even the maximum bulk temperature of $500^{\circ} \mathrm{F}$ recorded after $60 \mathrm{sec}$ of flame exposure was within the limit. Figure 10(a) shows the hot side of the Carbon- 3 specimen after all four tlame exposures. No damage can be seen after the first three tests with little if any damage evident after the final test. As shown in Table III, there was a recession of $0.029 \mathrm{in.}$ ( $13 \%$ of the compressed cross-section) measured after $180 \mathrm{sec}$. of exposure. The thermal barrier should never experience such a prolonged exposure to jets of hot gas in the actual rocket application.
The endurance tests performed on Carbon-6 revealed results slightly different than for Carbon-3. After 15 sec., the maximum temperature ranged from 2520 to $2730^{\circ} \mathrm{F}$ with temperature drops $\left(\mathrm{T}_{\text {hot }}-\mathrm{T}_{\text {hulk }}\right)$ that ranged from 2240 to $2560^{\circ} \mathrm{F}$. The maximum bulk temperature after $15 \mathrm{sec}$. was $280^{\circ} \mathrm{F}$, slightly higher than that for Carbon- 3 but still well below the Viton O-ring temperature limit. The Carhon- 6 series revealed a slightly higher maximum overall bulk temperature of $620^{\circ} \mathrm{F}$ that occurred in the final test after a 60 -sec. flame exposure. This temperature is about the maximum that the ()-rings can withstand for a short period of time. but as mentioned previously, the thermal barrier should not experience such a long flame exposure in the rocket.

Figure 10(b) shows the hot side of the Carbon-6 specimen after all four flame exposures. Very little damage can be seen after the first test. but the amount of damage to the specimen increased to a maximum recession of 0.092 in. (30\% of the compressed cross-section) after the final test. This recession likely contributed to the increased maximum bulk temperature in the final test. These temperature drop tests were all performed in a more aggressive oxidizing environment than the thermal barrier would experience in the rocket. The amount of damage observed on the Carbon- 6 specimen after 200 sec. of flame exposure would not be expected to occur in a less oxidizing environment with much shorter hot gas exposures.

For hoth series of tests. the flow through the specimen was almost identical from test to test. Flow rates through Carbon- 6 were higher than those through Carbon- 3 as is expected since Carbon- 6 is more porous than Carbon-3 (Table II).

\section{Flow Test Results}

Flow rates ( measured using the piston flow rig. Fig. 3) for Carbon-3, Carbon-4. and Carbon-6 at 20 and 25\% linear compression are summarized in Fig. 11 at 60 psid and 70,500 , and $9000^{\circ} \mathrm{F}$ after scrubbing and $70^{\circ} \mathrm{F}$ before scrubbing. Application of the thermal barrier in the Shuttle solid rocket motor nozzle-to-case joint involves predominantly static (e.g. no scrubbing) loads. As shown by the flow results, flow resistance increased with higher compression levels. Figure 11 shows that the flow rates for Carbon-6 were higher than those for Carbon- 3 and Carbon-4 at 60 psid at each temperature and compression level. Carbon-6 flow rates were 2.1 to 2.9 times higher than Carbon- 3 flow rates and 1.7 to 2.3 times higher than Carbon-4 flow rates at comparable temperatures and compression levels. This difference is due to differences in braid architecture between these thermal barrier designs. The difference in flow rates between Carbon- 3 and Carbon-4 was attributed to Carbon-4 incorporating larger core fihers resulting in higher seal porosity than Carbon-3. ${ }^{3}$ Carbon-fincorporating multiple sheath layers 
has a higher porosity than Carbon-3 (Table II) and is therefore more permeable. Discussions between the authors and rocket manufacturer Thiokol have indicated that the thermal barriers have high enough permeability to permit the joint-cavities to fill in acceptable times.

Effect of Temperature. Figure 11 shows that flow rates dropped for each thermal barrier as the temperature was increased. This phenomenon is explained by the relationship that gas viscosity increases with temperature, $\mu \alpha T^{2 / 3}$. Thus, as the viscosity of the gas flowing through the thermal barriers increased, the flow rate decreased.

Effect of Hot Scrubbing. Thermal barrier flow rates typically rose after hot scrubbing during flow tests. After $500{ }^{\circ} \mathrm{F}$ testing Carbon-6 How rates rose as much as $20 \%$ as compared to the flow rates before scrubbing. Post-scrub room temperature flows for all thermal barriers were done after time spent at $500^{\circ} \mathrm{F}(2 \mathrm{hr})$ and $900^{\circ} \mathrm{F}$ ( $\left.1.5 \mathrm{hr}\right)$. Postscrub room temperature flow rates for Carbon- 3 as much as doubled as compared to their pre-scrub values. Carbon-6 exhibited similar flow growth after scrubbing but flows for pressure differentials of 60 psid were not within the range of the flow meter used. It is believed that much of the flow rate increase is due to oxidation that occurred while the specimen soaked at these high temperatures. No major visible damage due to scrubbing was observed on any of the thermal barrier designs at the conclusion of the flow tests. Only minor fraying was observed at the specimen ends in the lap joint. Temperature exposure tests performed on carbon fiber thermal barriers ${ }^{3}$ showed that short lengths of carbon thermal barrier lost weight when heated in a furnace at different temperatures for two-hour exposures. This supported the theory that the carbon thermal barriers oxidized when exposed to temperatures of $900^{\circ} \mathrm{F}$ for extended periods of time, and the associated weight-loss contributed to the increased flow rates after scrubbing.

\section{Compression Test Results}

Table IV summarizes the results of the compression tests performed on Carbon- 3 and Carbon- 6 and includes the measured contact width. preload. and residual interference for each amount of linear compression, or crush, tested.

Contact Width. The contact width increased for the Carbon- 3 and -6 designs as the amount of linear crush was increased. The thermal barriers continued to spread and flatten out as they experienced larger amounts of compression. In each test, the footprint pattern left on the pressure sensitive film after a compression cycle was solid and continuous. This indicates that during a flow test continuous contact is made between the walls of the flow fixture and the thermal barrier, minimizing leakage past the specimen.
The contact width at each compression level for Carbon- 6 was over twice as large as it was for Carbon-3 even though the diameter of Carbon- 6 was only 1.3 times larger than for Carbon-3. This shows that Carbon- 6 had a softer, more compressible braid architecture than Carbon- 3 allowing Carbon- 6 to spread out more as it was compressed.

Preload. The amount of preload or footprint contact pressure increased with the amount of linear crush. However, Carbon- 6 had preloads that were $1 / 6$ th to $1 / 9$ th those for Carbon-3 at each compression level. As a result, Carbon- 6 will cause lighter loads on the adjoining rubber $\mathrm{J}$-leg element. The reason for this difference in preload is believed to be related to the architectures of these thermal barrier designs (Table I). In Carbon- 3 having a tightly packed core of uniaxial fibers, there is little room for individual fibers to move with respect to one another when they are compressed. In contrast, in Carbon-6 the sheath fibers are oriented at an angle with each other and are better able to slide past each other when the thermal barrier is compressed.

Residual Interference. As with the contact width and preload, thermal barrier residual interference or spring back also increased as percent linear crush increased. Although contact width and preload were quite different for Carbon-6 and Carbon-3, residual interference scaled with diameter for these two designs. Increasing thermal barrier diameter by a factor of 1.3 from 0.200 to 0.260 in. resulted in an increase in residual interference by that ratio for each level of compression. Residual interference for Carbon- 6 was 0.025 in. even for the lowest compression (20\%) and meets the design requirement to follow nozzle joint movement during Shuttle solid rocket motor operation, as discussed with rocket manufacturer Thiokol.

\section{Comparison of Carbon-3 and Carbon-6: Other Factors}

Carbon- 3 and Carbon- 6 both performed well in the temperature drop comparison tests. Carbon- 3 did offer somewhat greater insulating effects than Carbon- 6 and showed less recession than Carbon-6. We believe the higher density of Carbon-3 is an important reason for these results. However, there are many other factors to consider when deciding between these two braid architectures. Carbon- 6 is braided using larger tows or yarns that permits faster and therefore most cost-effective production. Carbon- 6 is a more flexible braid that makes it easier to spool for shipment and more accommodating during installation. The current tests combined with other planned rocket motor and joint-simulation tests will enable Thiokol and NASA to decide on the optimal braid architecture for the thermal harrier. 


\section{Results of Thiokol Char Motor Tests on Carbon Thermal Barrier}

Thiokol tested a 0.260 -in. diameter Carbon- 6 thermal barrier for NASA in a subscale rocket motor to verify that it would withstand the Shuttle solid rocket motor environment. The subscale motor, or "char" motor, simulates the thermal conditions of the full-scale motor by hurning solid rocket propellant at corresponding chamber pressure and temperature conditions. The thermal harrier was placed into an intentional gap defect between the phenolic insulation blocks, as shown in Fig. 12(a). The combination of an outboard plenum chamber and the 0.060 -in. circumferential gap extending both upstream and downstream of the thermal barrier ensured that hot gas flow would pass through the thermal barrier.

Throughout the test duration of $\sim 11 \mathrm{sec}$, a significant drop in temperature was measured across the thermal barrier. Figure 12(b) shows that the maximum temperature seen on the hot side of the thermal harrier was over $3200^{\circ} \mathrm{F}$, while the cold side temperature reached about $950^{\circ} \mathrm{F}$. Thus, atemperature drop of about $2200^{\circ} \mathrm{F}$ occurred across the 0.260-in. diameter thermal harrier. Pressure readings upstream and downstream of the thermal barrier and in the reservoir confirmed that there was gas flow across the thermal barrier. The thermal barrier diffused the focused nature of the hot gas jet. lurther reducing the jet's potentially damaging effects on downstream Viton O-rings in the actual Shuttle solid rocket motor.

Although the $950{ }^{\circ} \mathrm{F}$ temperature recorded downstream of the thermal harrier is still higher than the temperature limits of the Viton nozzle ()-rings. the char motor subjected the thermal barrier to more aggressive conditions than would ever occur in the actual Shuttle solid rocket motor, for the following reasons. First the gap defect was purposely oversized at 0.060 in. to force llow through the thermal barrier. In the actual nozzle joint, the gap between adjoining blocks of insulation would be narrower as the pieces of insulation are basically in contact with each other. The narrow gaps between the phenolic insulation would significantly cool the incoming gas temperature impinging on the thermal barrier and would therefore lower the temperature of the gas that reaches the Viton O-rings. Furthermore, the downstream temperature in the char motor test was recorded immediately downstream of the thermal barrier. The ()-rings in the rocket nozzle joint are located several inches further downstream of the thermal barrier, allowing additional heat to be removed from the gas before reaching the (O-rings.

Figure 13 shows the thermal barrier after it was removed from the char motor. There was no apparent burning or charring of the thermal barrier. In addition. Fig. 13 shows that the thermal barrier also acted as an effective slag barrier. The inset photo in the figure shows a close-up of an area where slag was trapped by the thermal barrier, preventing it from reaching the downstream O-rings. Minor fraying occurred in the area immediately around the lap joint during disassembly, but the specimen is otherwise in good condition.

\section{Comparison of Thiokol Char Motor Test Results to} NASA Temperature Drop Test Results

The fixture used to perform the temperature drop tests on the Carbon- 3 and Carbon- 6 thermal barriers was modelled after the char motor and the shuttle nozzle-tocase joint thermal conditions. The fixture was made out of phenolic material to simulate the material and boundary conditions that the thermal barrier would be exposed to in these other configurations. The thermal barrier specimens were subjected to $20 \%$ compression as they were in the char motor test and as planned for the rocket. The flame of the oxyacetylene torch that was used for the temperature drop tests was directed through a 0.084 -in. diameter hole in an iris plate to simulate a hot gas jet that the barriercould he exposed to in the rocket. Flame exposure times were intentionally longer than they would be in the rocket application to simulate extreme heating conditions.

Considering the results of Fig. 10 (NASA temperature drop fixture), tests were performed with hot side temperatures ranging from 2500 to nearly $3200{ }^{\circ} \mathrm{F}$. Carbon- 6 temperature drops ranged from 2240 to $2560^{\circ} \mathrm{F}-15 \mathrm{sec}$. into the test. These were somewhat greater than the 220()$^{\circ} \mathrm{F}$ temperature drop exhibited by Carbon- 6 in the char motor. The main reason for this difference is that 900 psi pressures were generated by the char motor. while only 10 psid pressures were applied across the thermal barrier in the temperature drop tests. The higher-pressure char motor test caused more hot gas to flow through the thermal thereby raising the downstream temperature causing a smaller temperature drop. Though there are some differences in the absolute results, the authors believe the laboratory temperature-drop test fixture simulates many of the key factors at work in the rocket. The laboratory setup permits quick and easy comparisons between competing architectures and can be used to generate thermal data to anchor thermal correlations under development.

\section{Summary and Conclusions}

The 5500+ $+{ }^{\circ} \mathrm{F}$ combustion gases in the Space Shuttle solid rocket motor are kept a safe distance away from the assembly joint seals by thick layers of insulation and by special compounds that fill the joint split-lines in the insulation. The current nozzle-to-case joint design incorporates primary, secondary and wiper (innermost) O-rings 
and polysulfide joint-fill compound. In the current design, I out of 7 motors experience hot gas to the wiper $\mathrm{O}$-ring. Though the condition does not threaten motor safety, evidence of hot gas to the wiper $\mathrm{O}$-ring results in extensive reviews before resuming flight. NASA and solid rocket motor manufacturer Thiokol are working to improve the nozzle-to-case joint design by implementing a more reliable $\mathrm{J}$-leg design (suceessfully used in the field and igniter joints) and the thermal barrier Carbon-6 described herein.

The thermal resistance of two NASA thermal barriers, denoted Carbon- 3 and Carbon- 6 , was assessed by exposing them to an oxyacetylene torch at $5500^{\circ} \mathrm{F}$ and measuring time for burn through. Temperature drop tests were performed to measure the temperature drop across and along the thermal barriers in a compressed state when subjected to the flame of an oxyacetylene torch. Flow and durability tests were conducted on the thermal barriers to examine their leakage characteristics and durability at ambient and high temperatures. Room temperature compression tests were performed to determine load versus linear compression, preload, contact area, and residual interference/ resiliency characteristics. Subscale rocket "char" motor tests were performed in which hot combustion gases were directed at the Carbon-6 thermal barrier to assess its thermal resistance in a rocket environment. The current tests combined with other planned rocket motor and joint simulation tests will enable Thiokol and NASA to decide on the optimal braid architecture for the thermal barrier. Based on the results of the current tests, the following conclusions are made:

1. The Carbon-6 (0.260-in. diam.) and Carbon-3 (0.20-in. diam.) thermal barrier resisted the $5500^{\circ} \mathrm{F}$ flame of an oxyacetylene torch for over $6 \mathrm{~min}$ before burn through. greater than three times the Shuttle solid rocket motor burn time.

2. Carbon- -3 and Carbon-6 thermal barriers were excellent insulators causing temperature drops through their diameter from 2500 to $28000^{\circ} \mathrm{F}$, depending on test parameters. Gas temperature $1 / 4^{\prime \prime}$ downstream of the thermal barrier were within the downstream Viton ()-ring temperature limit of $\leq 600^{\circ} \mathrm{F}$.

3. The Carbon-6 thermal barrier design performed extremely well in subscale rocket "char" motor tests that subjected it to hot gas at $3200^{\circ} \mathrm{F}$ for an 11 -sec. rocket firing, simulating the maximum downstream joint-cavity filltime. The thermal barrier reduced the incoming hot gas temperature by $2200{ }^{\circ} \mathrm{F}$ in an intentionally oversized gap defect, spread the incoming jet flow, and blocked hot slag. thereby offering protection to the downstream $\mathrm{O}$-rings.

4. Laboratory burn, temperature drop, flow, and compression tests and subscale rocket "char" motor tests demonstrate the thermal barrier's feasibility for use in rocket applications and qualify it for comprehensive motor evaluation.

\section{Relerences}

'Steinetz, B.M., Adams, M.L., Bartolotta, P.A., Darolia. R.. and Olsen, A., "High Temperature Braided Rope Seals for Static Sealing Applications," NASA TM-107233, rev., July 1996.

${ }^{2}$ Steinetz, B.M., and Adams, M.L., "Effects of Compression, Staging, and Braid Angle on Braided Rope Seal Performance," NASA TM-107504, July 1997.

${ }^{3}$ Steinetz, B.M., and Dunlap, P.H., "Feasibility Assessment of Thermal Barrier Seals for Extreme Transient Temperatures," NASA TM-208484, July 1998.

${ }^{4}$ Thiokol report TWR-73191, "RSRM-45A Nozzle Joint No. 30-ring Erosion Investigation Team-Final Report," Oclober 28.1996.

${ }^{5}$ Rogers, W.P., "Report of the Presidential Commission on the Space Shuttle Challenger Accident,"June 6 , 1986.

${ }^{6}$ Ballis, W., ASM Handbook, Volume 6: Welding, Brazing. and Soldering, ASM International, 1993, pp. 281-290.

${ }^{7}$ Bahl, O.P. and Dhami, T.L., "Oxidation Resistance of" Carbon Fibers," High Temperatures - High Pressures, Vol. 19, pp. 211-214, 1987.

${ }^{8}$ Eckstein, B.H. and Barr, J.B., "An Accelerated Oxidation Test for Oxidation Resistant Carbon Fibers,"MaterialsProcesses: The Intercept Point; Proceedings of the Twentieth International SAMPE Technical Conference, Minneapolis, MN, Sept. 27-29, 1988. Covina, CA. Socicty for the Advancement of Materials and Process Engineering, 1988, pp. 379-391.

${ }^{9}$ Eckstein, B.H., "The Weight Loss of Carbon Fibers in Circulating Air," 18 th International SAMPE Technical Conference, October 7-9, 1986, pp. 149-160.

${ }^{10}$ Lide and Kehiaian, CRC Handbook of Thermophysical and Thermochemical Dala. CRC Press, 1994. pp. 25-31.

${ }^{11}$ Parker O-ring Handbook, Cleveland, OH, 1992. 
TABLE I.-THERMAL BARRIER CONSTRUCTION MATRIX

\begin{tabular}{|c|c|c|c|c|c|c|c|c|c|c|c|c|}
\hline \multirow{2}{*}{$\begin{array}{l}\text { Barrier } \\
\text { type }\end{array}$} & \multirow{2}{*}{$\begin{array}{l}\text { Size } \\
\begin{array}{l}\text { Dianteter, } \\
\text { in. }\end{array}\end{array}$} & \multicolumn{4}{|c|}{ Core } & \multicolumn{7}{|c|}{ Sheath } \\
\hline & & Material & Denier & $\begin{array}{c}\text { Fiber } \\
\text { diameter, } \\
\text { in." }\end{array}$ & $\begin{array}{l}\text { Number } \\
\text { of yarns }\end{array}$ & Malerial & Denier & $\begin{array}{c}\text { Fiber } \\
\text { diameter. } \\
\text { in." }\end{array}$ & $\begin{array}{c}\text { Number of } \\
\text { layers }\end{array}$ & $\begin{array}{c}\text { Number of } \\
\text { carriers } \\
\text { per layer }\end{array}$ & $\begin{array}{c}\text { Number of } \\
\text { yarns per } \\
\text { bundle }\end{array}$ & $\begin{array}{l}\text { Braid } \\
\text { angle. } \\
\text { degrees } \\
\end{array}$ \\
\hline \multicolumn{13}{|c|}{ Carbon } \\
\hline Carbon- I & 0.114 & $\begin{array}{c}\text { Grafil } \\
34-70012 \mathrm{~K} \\
\end{array}$ & 7200 & $2.76 \times 10^{-1}$ & 4 & $\begin{array}{l}\text { Thornel' } \\
\mathrm{T}-300) 1 \mathrm{~K}\end{array}$ & 600 & $2.8 \times 10^{5}$ & 5 & 8 & $\mathrm{~T}$ & 4.5 \\
\hline Carbon-2 & 0.125 & $\begin{array}{c}\text { Grafil } \\
34-70012 \mathrm{~K} \\
34-70013 \mathrm{~K}\end{array}$ & $\begin{array}{l}7200 \\
1800\end{array}$ & $2.76 \times 10^{-3}$ & I & $\begin{array}{l}\text { Thonel } \\
T-3001 \mathrm{~K}\end{array}$ & 600 & $2.8 \times 10^{5}$ & I0) & 8 & $\mathrm{I}$ & 45 \\
\hline Carbon-2A & 0.125 & $\begin{array}{c}\text { Grafil } \\
34-70012 \mathrm{~K} \\
34-7003 \mathrm{~K}\end{array}$ & $\begin{array}{l}7200 \\
18000\end{array}$ & $2.76 \times 10^{4}$ & $\begin{array}{l}1 \\
1\end{array}$ & $\begin{array}{c}\text { Thornel } \\
\mathrm{T}-3(01) \mid \mathrm{K}\end{array}$ & 600 & $2.8 \times 10^{4}$ & 9 & 8 & ] & 45 \\
\hline Carbon-3 & 0.200 & $\begin{array}{c}\text { Grafil } \\
34-700) 12 \mathrm{~K}\end{array}$ & 7200 & $2.76 \times 10^{1}$ & 10 & $\begin{array}{c}\text { Thonel } \\
\mathrm{T}-300) \text { IK } \\
\end{array}$ & 600 & $2.8 \times 10^{4}$ & 5 & $\begin{array}{l}12 \text { in } 1-2 \\
24 \text { in } 3-5\end{array}$ & I & $\begin{array}{l}6.5 \text { in }]^{41} \\
60 \text { in } 5^{1}\end{array}$ \\
\hline Carbon-4 & 0.194 & $\begin{array}{l}\text { Amoco! } \\
\text { P25 2K }\end{array}$ & 2900 & $4.4 \times 10^{-4}$ & 21 & $\begin{array}{c}\text { Thornel } \\
\mathrm{T}-3001 \mathrm{~K}\end{array}$ & 600 & $2.8 \times 10^{4}$ & 5 & $\begin{array}{l}12 \text { in } 1-2 \\
24 \text { in } 3-5 \\
\end{array}$ & 1 & $\begin{array}{l}6.5 \text { in } 1^{\circ 1} \\
60) \text { in } 5^{118} \\
\end{array}$ \\
\hline Carbon-6 & 0.260 & $\begin{array}{c}\text { Grafil } \\
34-70() 12 \mathrm{~K}\end{array}$ & 72010 & $\begin{array}{c}2.76 \times 10^{-4} \\
\end{array}$ & 1 & $\begin{array}{c}\text { Thornel } \\
T-300) 1 \mathrm{~K} \\
\mathrm{~T}-300,3 \mathrm{~K}\end{array}$ & $\begin{array}{l}600 \\
1800\end{array}$ & $2.8 \times 10^{4}$ & 10 & $\begin{array}{c}8 \text { in } 1-5 \\
12 \text { in } 6-7 \\
16 \text { in } 8-10\end{array}$ & 1 & $\begin{array}{c}17 \text { in } 1^{\prime} \\
45 \text { in } 2-10\end{array}$ \\
\hline \multicolumn{13}{|c|}{ All-Ceramic } \\
\hline NTWAC-2 & 0.120 & $\mathrm{NX} 5.50^{2}$ & 700 & $3.2 \times 10^{-1}$ & 109 & NX 550 & 700 & $3.2 \times 10^{4}$ & 2 & 8 & 1 & 56 \\
\hline
\end{tabular}

TABLE II -MEASURED THERMAL BARRIER POROSITY AT 20\% COMPRESSION

\begin{tabular}{|c|c|c|c|c|c|}
\hline $\begin{array}{c}\text { Thermal } \\
\text { barrier type }\end{array}$ & $\begin{array}{c}\text { Number of } \\
\text { sheath layers }\end{array}$ & $\begin{array}{c}\text { Diameter, } \\
\text { in. }\end{array}$ & $\begin{array}{c}\text { Thermal barrier } \\
\text { density, lb/cu.in. }\end{array}$ & $\begin{array}{c}\text { Carbon fiber } \\
\text { density, Ib/ cu.in. }\end{array}$ & Porosity \\
\hline Carbon-3 & 5 & 0.200 & 0.041 & 0.064 & 0.37 \\
\hline Carbon-6 & 10 & 0.260 & 0.032 & 0.064 & 0.50 \\
\hline
\end{tabular}

${ }^{2}$ Porosity $=1-\rho_{18} / \rho_{[1]}$.

TABLE III -TEMPERATURE DROP TEST RESULTS

\begin{tabular}{|c|c|c|c|c|c|c|c|c|c|c|}
\hline \multirow{2}{*}{$\begin{array}{c}\text { Test } \\
\text { number }\end{array}$} & \multicolumn{2}{|c|}{ Exposure time } & \multirow{2}{*}{$\begin{array}{c}T_{\text {ln, }} \text { al } \\
15 \mathrm{sec} . \\
{ }^{\circ} \mathrm{F}\end{array}$} & \multirow{2}{*}{$\begin{array}{l}T_{\text {hill }} \text { al } \\
15 \mathrm{sec} \text {. } \\
{ }^{\circ} \mathrm{F}\end{array}$} & \multirow{2}{*}{$\begin{array}{c}\mathrm{T}_{1,1,1}-\mathrm{T}_{\text {nulh }} \\
\text { at } 1.5 \text { seco. } \\
{ }^{\circ} \mathrm{F}\end{array}$} & \multirow{2}{*}{$\begin{array}{l}T_{\mathrm{hul}}-\mathrm{T}_{\text {candut }} \\
\text { at } 1.5 \mathrm{sec} \text {. } \\
{ }^{\circ} \mathrm{F}\end{array}$} & \multirow{2}{*}{$\begin{array}{l}\text { Flow at } \\
15 \mathrm{sec} \text {. } \\
\mathrm{SCFM} / \mathrm{in} \text {. }\end{array}$} & \multirow{2}{*}{$\begin{array}{c}\mathrm{T}_{\text {milk }} \\
\text { maximum, } \\
{ }^{\circ} \mathrm{F}\end{array}$} & \multicolumn{2}{|c|}{$\begin{array}{c}\text { Recession atier } \\
\text { test }\end{array}$} \\
\hline & $\begin{array}{c}\text { Per lest, } \\
\text { see }\end{array}$ & $\begin{array}{l}\text { Accumulated. } \\
\text { sec }\end{array}$ & & & & & & & in. & Percent \\
\hline 30 & 30 & 30 & 3070 & 210 & $28(4)$ & 2330 & 0.14 & 310 & --- & $\overline{---}$ \\
\hline 31 & 30 & 60 & 30.50 & 230 & 2820 & 2300 & .14 & 340 & --- & --- \\
\hline 32 & 60 & 120 & 3020 & 200 & 2820 & 2250 & .14 & 500 & $-\cdots$ & --- \\
\hline 33 & 60 & 180 & 2590 & 150 & 2440 & 1920 & .14 & 340 & 0.029 & 13 \\
\hline
\end{tabular}

(h) Carhon-6 Temperature Drop Test Results

\begin{tabular}{|c|c|c|c|c|c|c|c|c|c|c|}
\hline \multirow[t]{2}{*}{$\begin{array}{c}\text { Test } \\
\text { number }\end{array}$} & \multicolumn{2}{|c|}{ Exposure time } & \multirow{2}{*}{$\begin{array}{c}T_{\text {Im! }} \text { al } \\
15 \text { sec. } \\
{ }^{\circ} \mathrm{F}\end{array}$} & \multirow{2}{*}{$\begin{array}{c}\mathrm{T}_{\text {bulk }} \text { at } \\
15 \mathrm{sec} \text {. } \\
\mathrm{of}\end{array}$} & \multirow{2}{*}{$\begin{array}{c}T_{\text {tr:1 }}-\mathrm{T}_{\text {trulk }} \\
\text { at } 1.5 \mathrm{sec} \text {. } \\
{ }^{\circ} \mathrm{F}\end{array}$} & \multirow{2}{*}{ 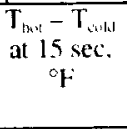 } & \multirow{2}{*}{$\begin{array}{l}\text { Flow at } \\
15 \mathrm{sec} \text {, } \\
\text { SCFM/in. }\end{array}$} & \multirow{2}{*}{$\begin{array}{c}\mathrm{T}_{\text {hullh }} \\
\text { maximum. } \\
{ }^{\circ} \mathrm{F}\end{array}$} & \multicolumn{2}{|c|}{$\begin{array}{c}\text { Recession after } \\
\text { test }\end{array}$} \\
\hline & $\begin{array}{l}\text { Per test, } \\
\text { sec }\end{array}$ & $\begin{array}{l}\text { Accumulated. } \\
\text { sec }\end{array}$ & & & & & & & in. & Percent \\
\hline 35 & 30 & 50 & 2730 & 170 & $2560)$ & 2050 & 0.24 & 320 & --- & --- \\
\hline 36 & 30 & 80 & 2690 & 190 & 2500 & 1960 & 0.24 & 350 & --- & --- \\
\hline 37 & 60 & 140 & 2520 & 280 & 2240 & 1760 & 0.25 & 480 & --- & --- \\
\hline 38 & 60) & 200 & 2700 & 280 & 2420 & 1700 & 0.24 & 620 & 0.092 & 30 \\
\hline
\end{tabular}


TABLE IV - -THERMAL BARRIER CONTACT WIDTH, PRELOAD, AND RESIDUAL INTERFERENCE FOR SEVERAL LINEAR CRUSH CONDITIONS

\begin{tabular}{|c|c|c|c|c|c|c|c|}
\hline $\begin{array}{c}\text { Thermal } \\
\text { barrier } \\
\text { type }\end{array}$ & $\begin{array}{c}\text { Diameter, } \\
\text { in. }\end{array}$ & $\begin{array}{c}\text { Nominal percent } \\
\text { linear crush. } \\
\text { percent }\end{array}$ & $\begin{array}{c}\text { Linear } \\
\text { crush. } \\
\text { in. }\end{array}$ & $\begin{array}{c}\text { Number of } \\
\text { sheath } \\
\text { layers }\end{array}$ & $\begin{array}{c}\text { Contact } \\
\text { width. } \\
\text { in. }\end{array}$ & $\begin{array}{c}\text { Preload, } \\
\text { psi }\end{array}$ & $\begin{array}{c}\text { Residual } \\
\text { interference, } \\
\text { in. }\end{array}$ \\
\hline Carbon-3 & 0.2 & 20 & 0.040 & 5 & 0.063 & 310 & 0.019 \\
& & 25 & .050 & & .082 & 490 & .027 \\
\hline Carbon-6 & 0.26 & .30 & .060 & & .099 & 930 & .033 \\
& & 20 & 0.052 & 10 & 0.157 & 56 & 0.025 \\
& 25 & .065 & & .192 & 80 & .036 \\
\hline
\end{tabular}

"Residual interference is defined as the distance that the thermal barrier will spring back while maintaining a load of at least I lb/in. of specimen.

(a)

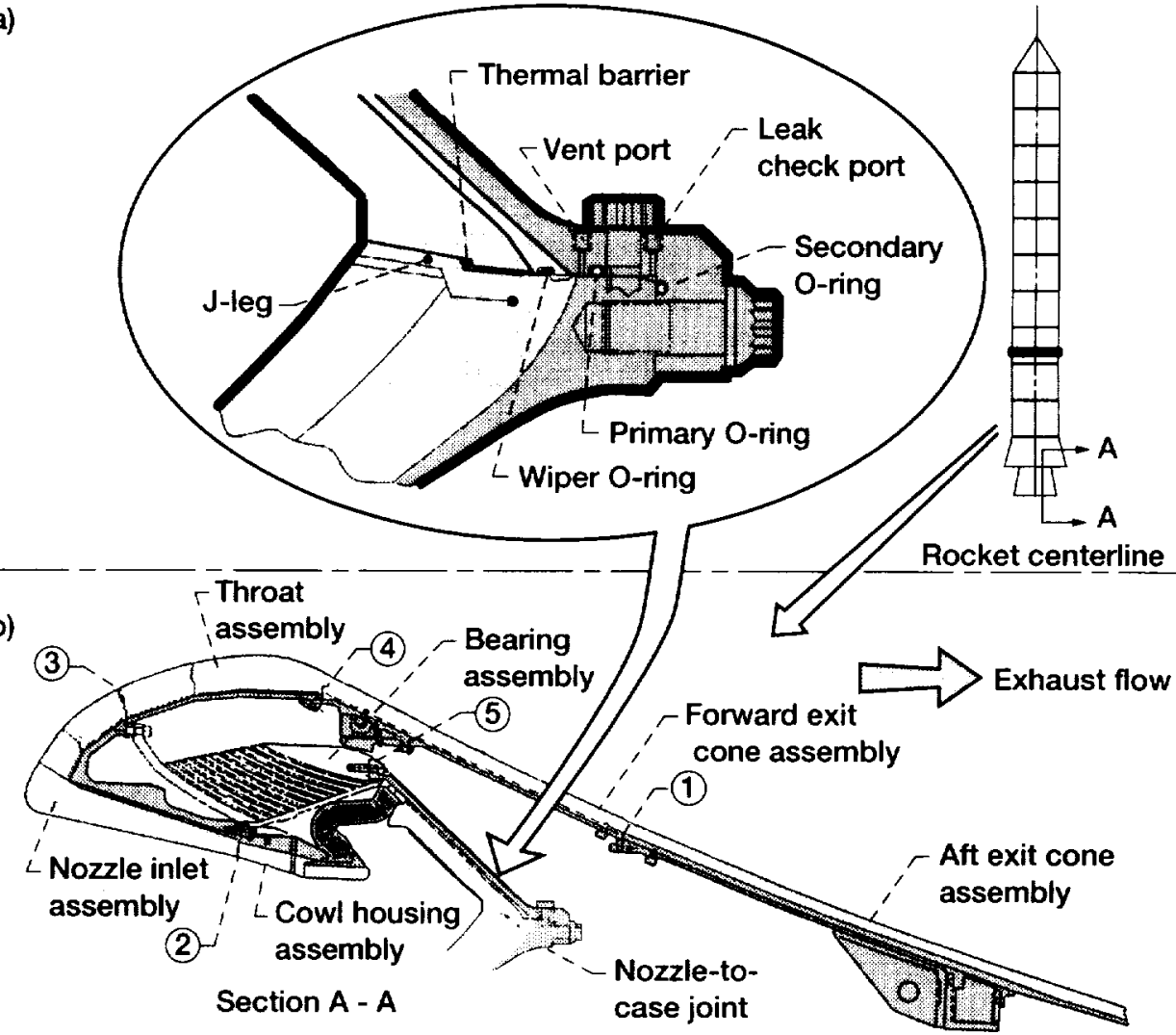

Figure 1.-Potential Shuttle solid rocket motor joint locations for thermal barrier. (a) Enlarged view of nozzle-to-case joint showing J-leg, wiper, primary, and secondary O-rings, leak-check port, and proposed thermal barrier location. (b) Overall nozzle cross-section (half view). 


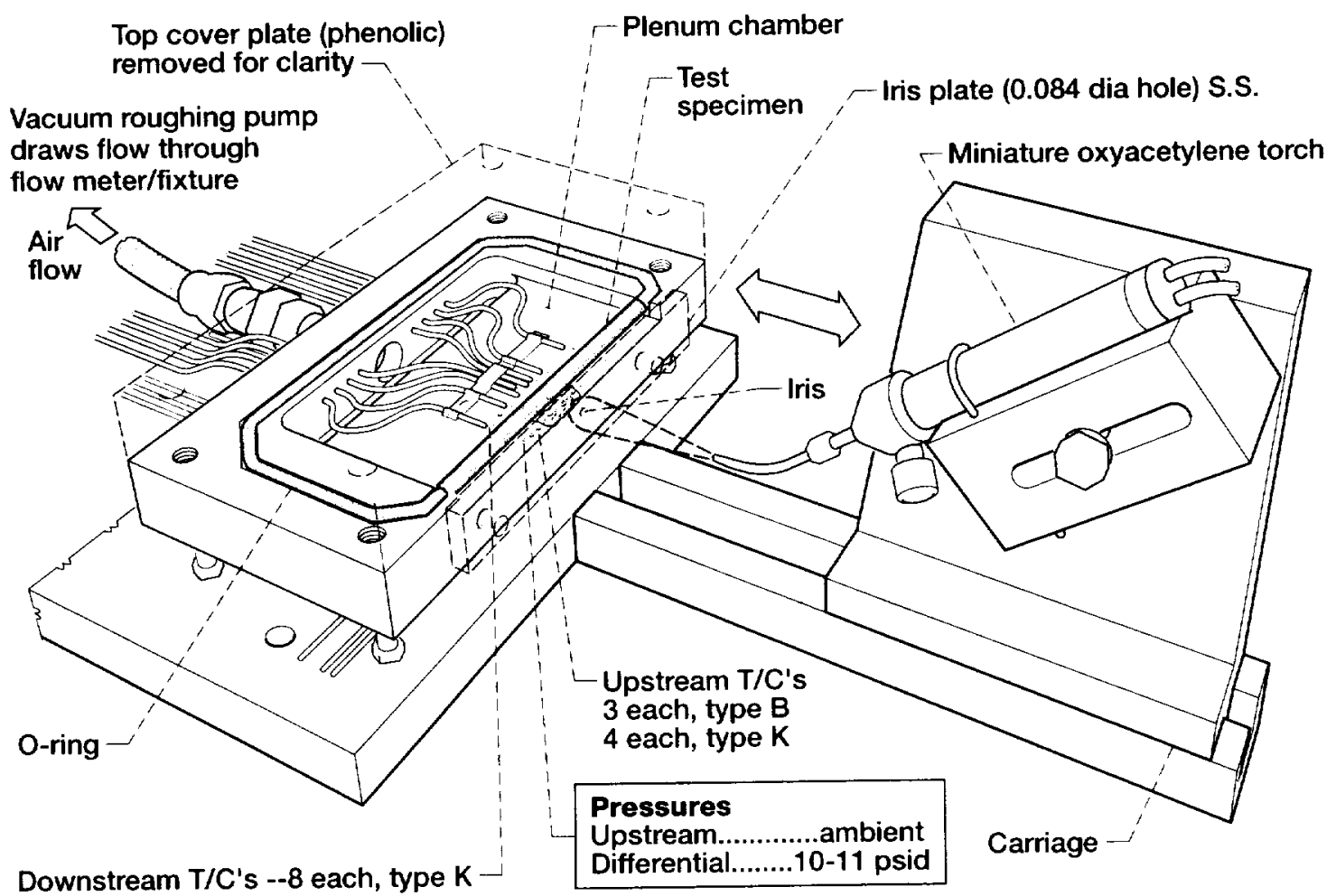

Figure 2.-Schematic of temperature drop test fixture.

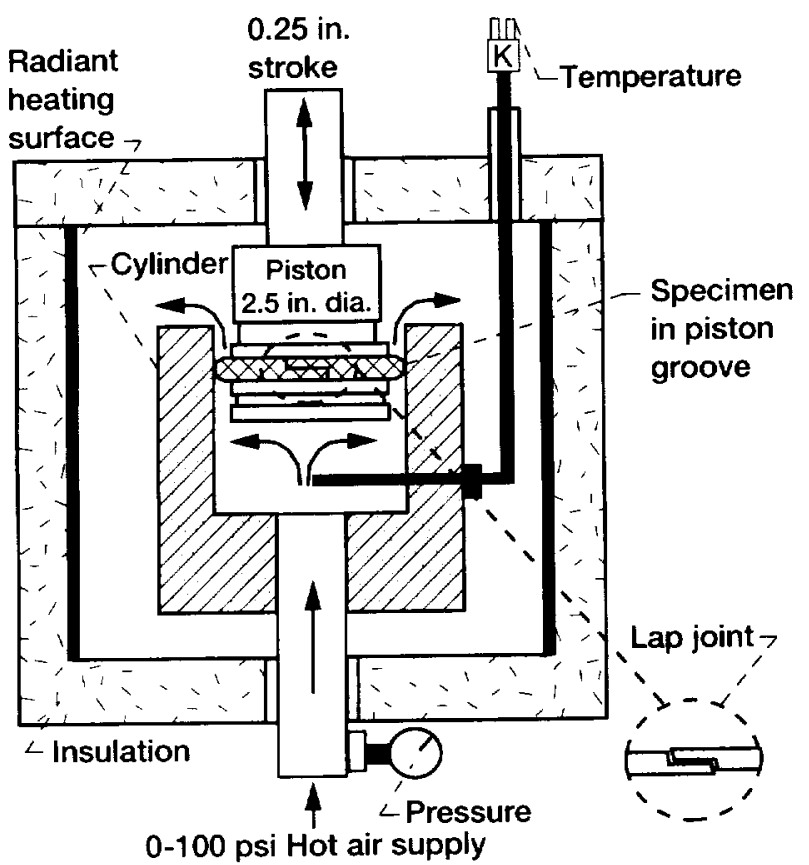

Figure 3.-Schematic of flow fixture.

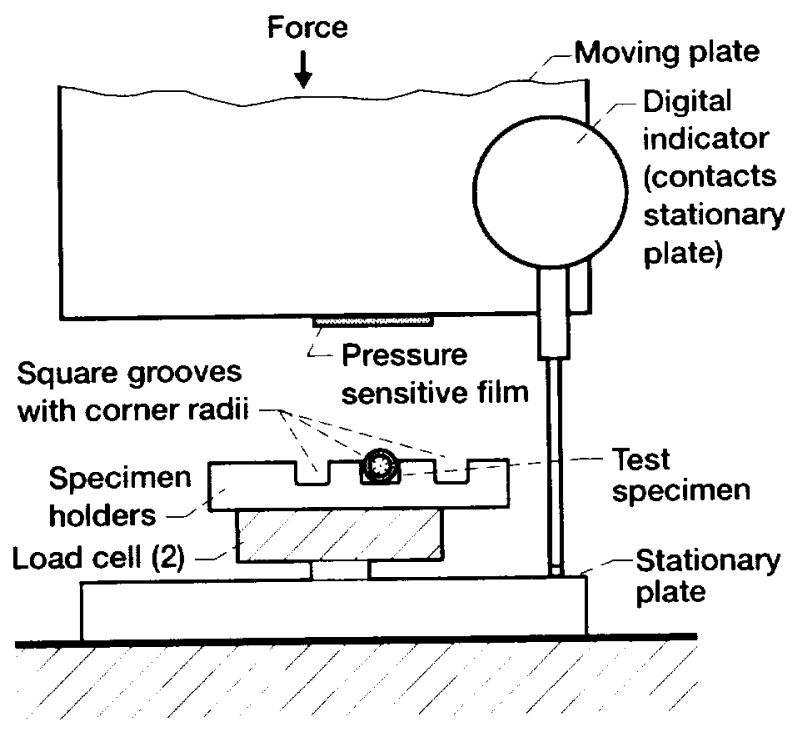

Figure 4.-Schematic of compression fixture. 


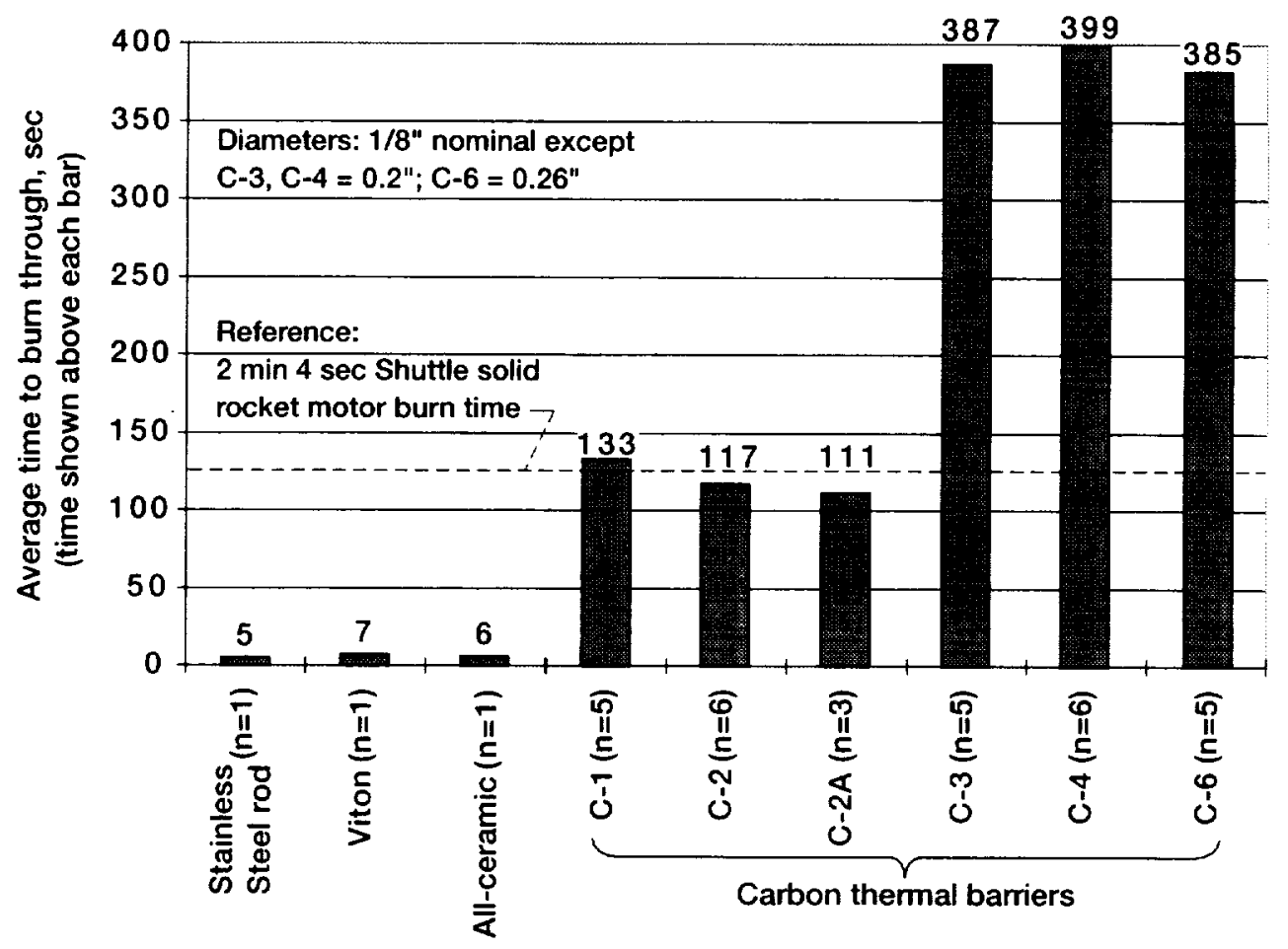

Figure 5.-Oxyacetylene torch burn test results ( $n=$ number of tests performed).

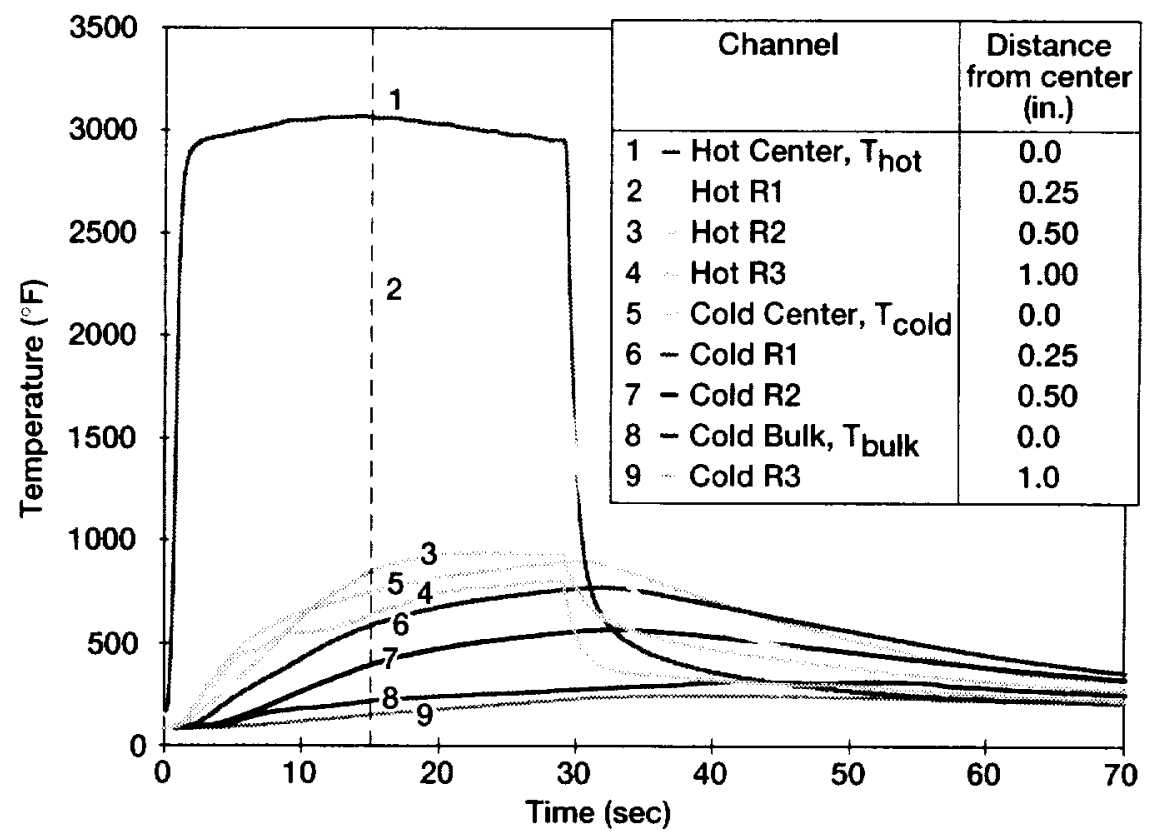

Figure 6.-Temperature rise vs. time for simulated hot gas exposure showing upstream (hot) and downstream (cold) temperatures for Carbon-3. Left hand temperatures removed for clarity. 


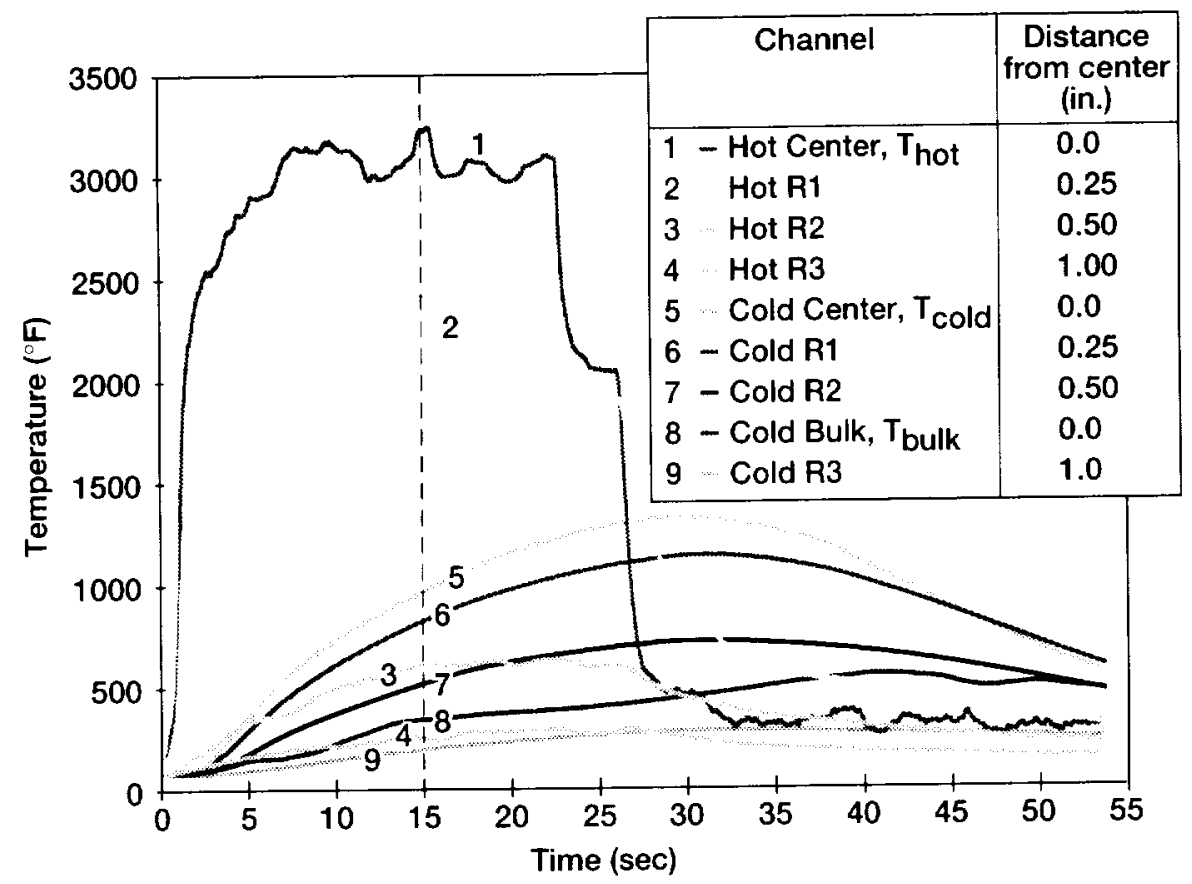

Figure 7.-Temperature rise vs. time for simulated hot gas exposure showing upstream (hot) and downstream (cold) temperatures for Carbon-6. Left hand temperatures removed for clarity.

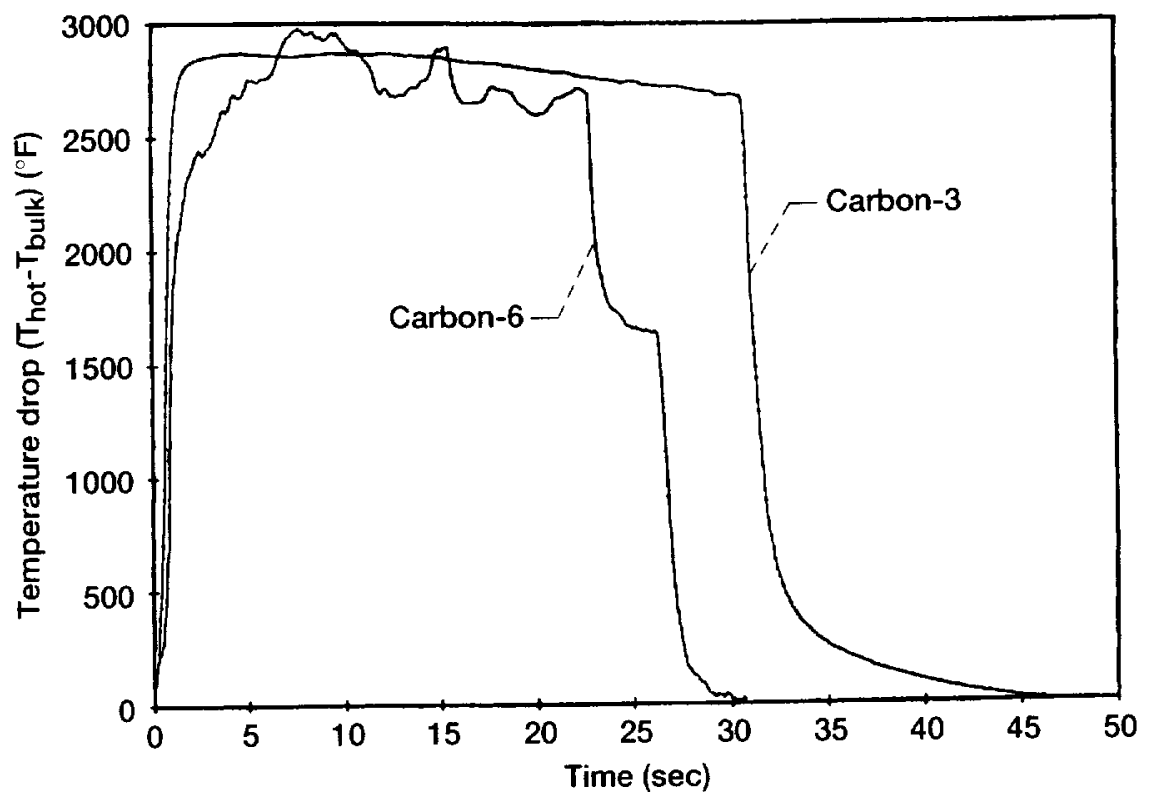

Figure 8.-Temperature drop vs. time $\left(T_{\text {hot }}-T_{\text {bulk }}\right)$ at flame location for Carbon- 3 and Carbon- 6 . 

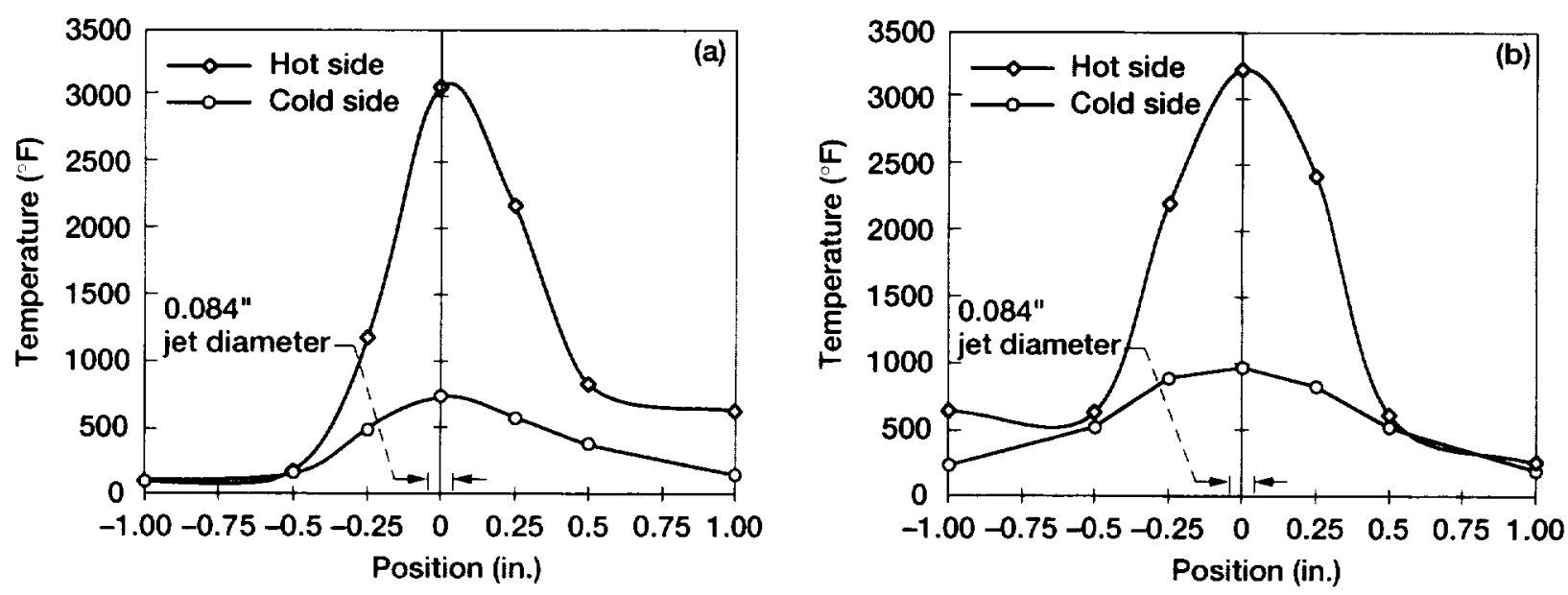

Figure 9.-Hot side and cold side temperatures versus axial position at 15 seconds showing jet $(0.082$ in. diameter) spreading for thermal barriers (a) Carbon-3; (b) Carbon-6. 

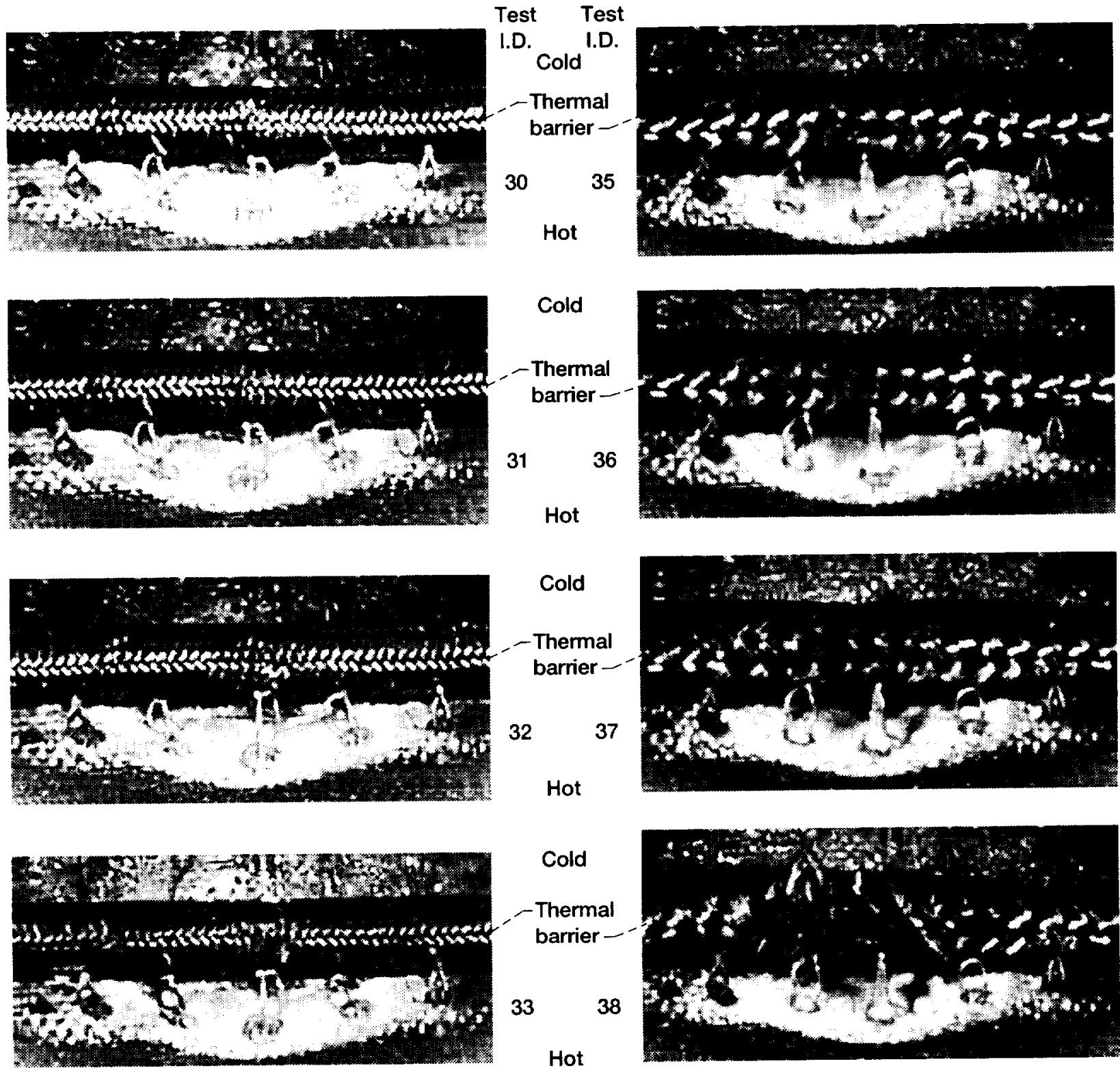

(a) Carbon-3 Temperature Drop Test Results

\begin{tabular}{|r|c|c|c|c|c|}
\hline Test \# & \multicolumn{2}{|c|}{ Exposure Time } & $T_{\text {hot }}$ & $T_{\text {bulk }}$ & $T_{\text {hot }}{ }^{-} T_{\text {bulk }}$ \\
\hline & Per test & Accumulated & $@ 15 \mathrm{sec}$ & $@ 15 \mathrm{sec}$ & $@ 15 \mathrm{sec}$ \\
\hline & $(\mathrm{sec})$ & $(\mathrm{sec})$ & $\left({ }^{\circ} \mathrm{F}\right)$ & $\left({ }^{\circ} \mathrm{F}\right)$ & $\left({ }^{\circ} \mathrm{F}\right)$ \\
\hline 30 & 30 & 30 & 3070 & 210 & 2860 \\
\hline 31 & 30 & 60 & 3050 & 230 & 2820 \\
\hline 32 & 60 & 120 & 3020 & 200 & 2820 \\
\hline 33 & 60 & 180 & 2590 & 150 & 2440 \\
\hline
\end{tabular}

(b) Carbon-6 Temperature Drop Test Results

\begin{tabular}{|c|c|c|c|c|c|}
\hline \multirow[t]{2}{*}{ Test\# } & \multicolumn{2}{|c|}{ Exposure Time } & $T_{\text {hot }}$ & $T_{\text {bulk }}$ & $T_{\text {hot }}-T_{\text {bulk }}$ \\
\hline & Per test & Accumulated & $@ 15 \mathrm{sec}$ & $@ 15 \mathrm{sec}$ & $@ 15 \mathrm{sec}$ \\
\hline & (sec) & $(\mathrm{sec})$ & ( $\mathrm{F})$ & $\left({ }^{\circ} \mathrm{F}\right)$ & $\left({ }^{\circ} \mathrm{F}\right)$ \\
\hline 35 & 30 & 50 & 2730 & 170 & 2560 \\
\hline 36 & 30 & 80 & 2690 & 190 & 2500 \\
\hline 37 & 60 & 140 & 2520 & 280 & 2240 \\
\hline 38 & 60 & 200 & 2700 & 280 & 2420 \\
\hline
\end{tabular}

Figure 10.-Thermal barrier condition and key temperatures versus accumulated time. (a) Carbon-3, (b) Carbon-6. 


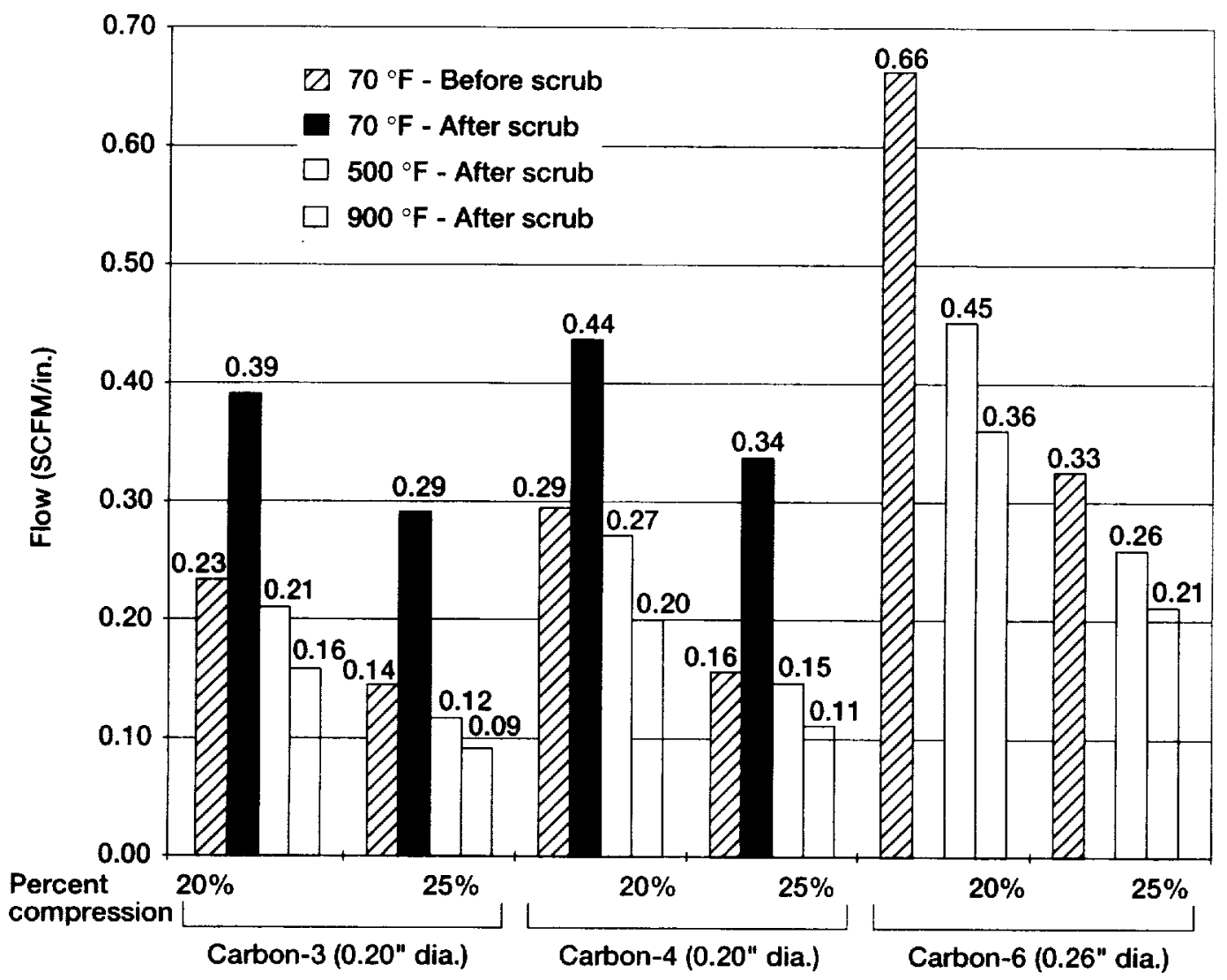

Figure 11.-The effect of temperature, thermal barrier type, scrubbing and compression on flow, $\Delta P=60$ psid.

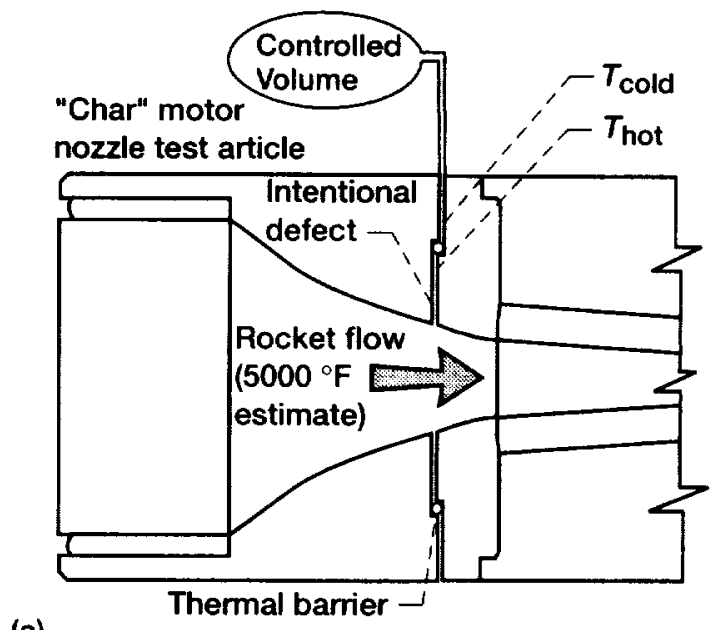

(a)

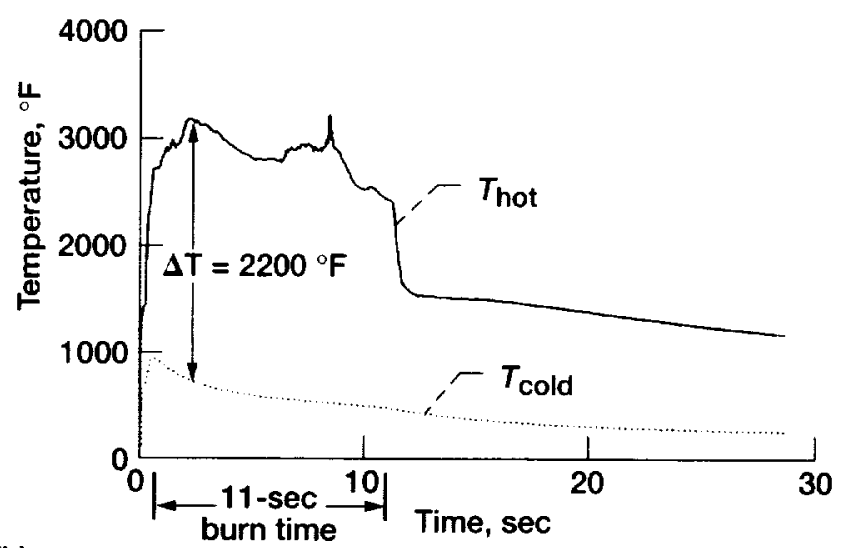

(b)

Figure 12.-Subscale (70 lbm) "char" motor tests examining thermal barrier (Carbon-6) effectiveness. (a) Test configuration: Carbon- 6 thermal barrier impedes hot gas flow through intentional joint defect (0.06 in. gap). (b) Temperature data: Upstream $\left(T_{\text {hot }}\right)$ and downstream $\left(T_{\text {cold }}\right)$ sides of thermal barrier. (Courtesy of Thiokol Corp.) 


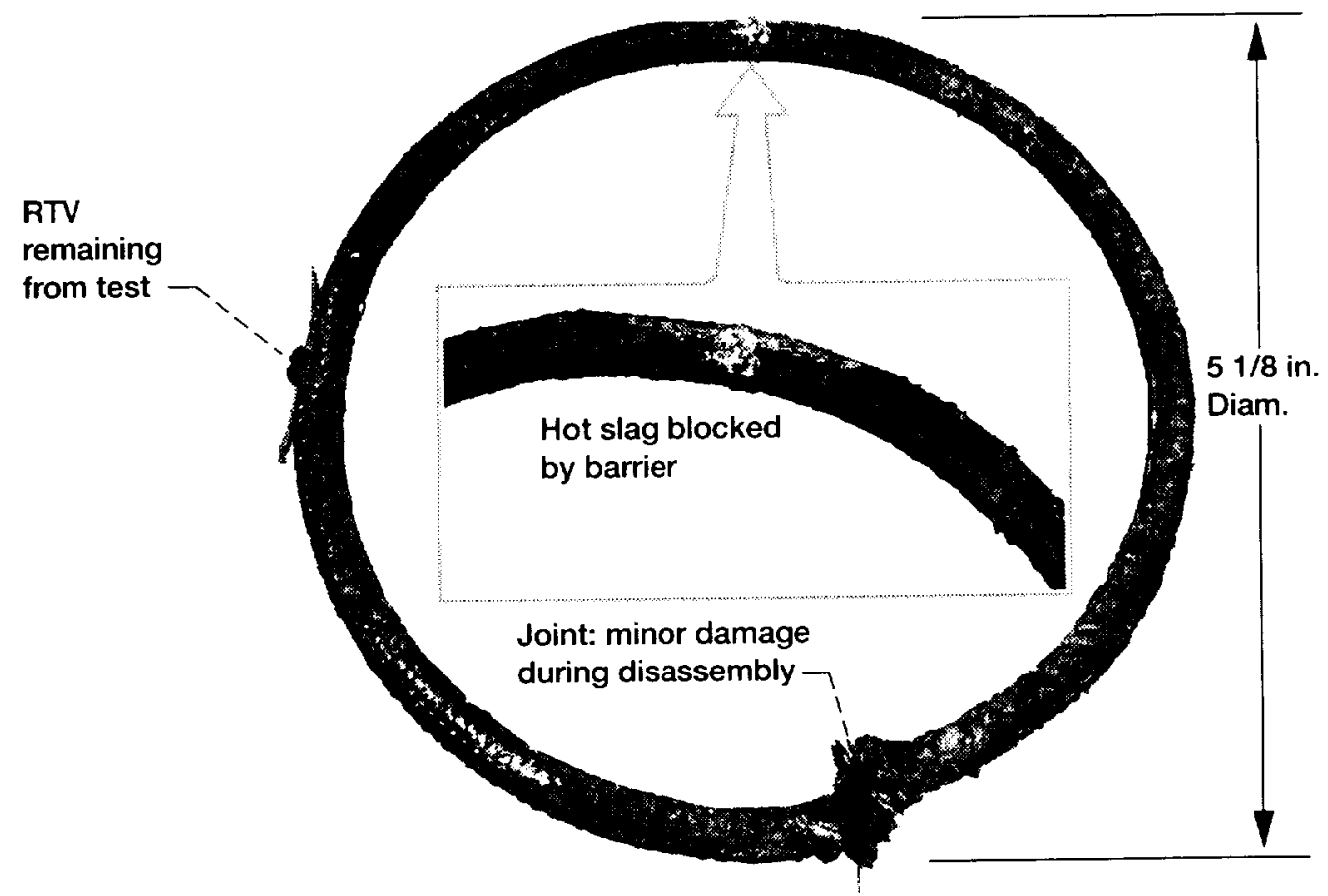

Figure 13.-Photograph of char motor thermal barrier (Carbon-6) after test. Thermal barrier effectively blocks $3200^{\circ} \mathrm{F}$ gas for 11 sec. (joint fill time) and blocks hot slag. (Courtesy of Thiokol Corp.) 
Public reponing burden for this coliection of intormation is estimated to average 1 hour per response, including the time for reviewing instructions, searching existing dala sources gathering and mainlaining the data needed. and completing and reviewing the collection of information. Send comments regarding this burden estimate or any other aspect of this

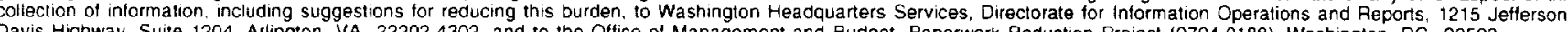
Davis Highway. Suite 1204. Arlington. VA 22202-4302, and to the Office of Management and Budget. Paperwork Reduction Project (0704-0188), Washington, DC 20503.

\begin{tabular}{|l|c|c|}
\hline 1. AGENCY USE ONLY (Leave blank) & $\begin{array}{c}\text { 2. REPORT DATE } \\
\text { June } 1999\end{array}$ & $\begin{array}{r}\text { 3. REPORT TYPE AND DATES COVERED } \\
\text { Technical Memorandum }\end{array}$ \\
\hline
\end{tabular}

\section{TITLE AND SUBTITLE}

Development of Thermal Barriers for Solid Rocket Motor Nozzle Joints 6. AUTHOR(S)

$$
\text { WU }-523-53-1.3-(0)
$$

Bruce M. Steinctz and Patrick H. Dunlap, Jr.

\section{PERFORMING ORGANIZATION NAME(S) AND ADDRESS(ES)}

National Acronautics and Space Administration

John H. Glenn Research Center at Lewis Field

Cleveland. Ohio 44135-3191

\section{SPONSORING/MONITORING AGENCY NAME(S) AND ADDRESS(ES)}

National Acronautics and Space Administration

Washington. DC 20546-0001
8. PERFORMING ORGANIZATION REPORT NUMBER

$E-11738$

11. SUPPLEMENTARY NOTES

Prepared for the 35th Joint Propulsion Conference \& Exhibit cosponsored by AIAA ASME, SAE, and ASEE. Los Angeles. California. June 20-24, 1999.

12a. DISTRIBUTION/AVAILABILITY STATEMENT 12b. DISTRIBUTION CODE

Unclassified - Unlimited

Subject Calegory: 37

Distribution: Nonstandard

This publicaltion is available from the NASA Center for AeroSpace Intormation. (301) 621-0390.

13. ABSTRACT (Maximum 200 words)

The Space Shutlce solid rocket motor casc assembly joints are sealed using conventional O-ring seals. The $5500+^{\circ} \mathrm{F}$ combustion gases are kept a safe dislance away from the seals by thick layers of insulation. Special joint-fill compounds are used to fill the joints in the insulaion to prevent a direct flowpath to the seals. (On a number of (ccasions. NASA has observed in several of the rocket nozzle assembly joints hot gas penetration through defects in the jointfill compound. The current nozzle-to-case joint design incorporates primary, secondary and wiper (inner-tmost) O-rings and polysulfide joint-fill compound. In the current design. 1 out of 7 motors experience hot gas to the wiper 0 -ring. Though the condition does not threaten motor safety, evidence of hot gas to the wiper ()-ring results in extensive reviews before resuming flight. NASA and solid rocket motor manufacturer Thiokol are working to improve the nozzle-to-case joint design by implenwenting a more reliable J-leg design and a thermal barrier. This paper presents burn-resistance. temperature drop. flow, and resiliency test results for several types of NASA braided carbon-fiber thermal harriers. Burn tests were performed to determine the time to bum through each of the thermal barriers when exposed to the flane of an oxy-acetylene torch $(550){ }^{\circ} \mathrm{F}$ ). representative of the $5500^{\circ} \mathrm{F}$ solid rocket motor combustion temperatures. Thermal barriers braided out of carbon fibers endured the flante for over 6 min. three times longer than solid rocket motor burn timt. Tests were perfonned on two thermal barrier braid architectures, denoted Carbon- 3 and Carbon- 6 , to measure the temperature drop across and along the barrier in a compressed state when subjected to the flame of an oxyacetylene torch. Carbon-3 and Carbon-6 thermal barriers were excellent insulators causing (cmperature drops through their diameter of up to a $280($ ) and 2560 "F. respectively. Gas temperature 1/4" downstream of the thermal barrier were within the downstream Viton O-ring temperature limit of $600{ }^{\circ} \mathrm{F}$. Carbon-6 performed extrenely well in subscale rocket "char" motor tests when subjected to hot gas at $3200^{\circ} \mathrm{F}$ for an 11 -sec. rocket firing. simulating the maximum downstream joint cavity fill time. The thermal barrier reduced the incoming hot gas temperature by $22(0)^{\circ} \mathrm{F}$ in an intentionally oversized gap defect, spread the incoming jet flow, and blocked hot slag. thereby offering protection to the downstrean (O-rings.

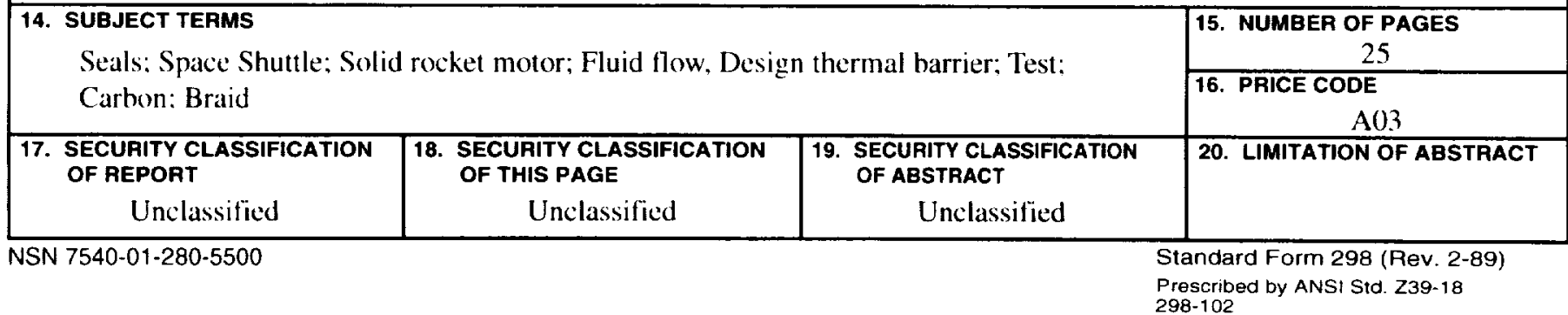

